\title{
Neuroprotective Herbs and Foods from Different Traditional Medicines and Diets
}

\author{
Marcello Iriti $^{1,2, *}$, Sara Vitalini ${ }^{1,3}$, Gelsomina Fico ${ }^{3,4}$ and Franco Faoro ${ }^{1,2}$
}

1 Dipartimento di Produzione Vegetale, Università degli Studi di Milano, Milano, Italy

2 Dipartimento Agroalimentare, CNR-IVV, Milano, Italy; E-Mail franco.faoro@unimi.it (F.F.)

3 Orto Botanico 'GE Ghirardi', Università degli Studi di Milano, Toscolano Maderno, Brescia, Italy; E-Mail: sara.vitalini@unimi.it (S.V.)

4 Dipartimento di Biologia, Università degli Studi di Milano, Milano, Italy;

E-Mail: gelsomina.fico@unimi.it (G.F.)

* Author to whom correspondence should be addressed; E-Mail: marcello.iriti@unimi.it; Tel.: +39-02-503-16766; Fax: +39-02-503-16781.

Received: 21 February 2010; in revised form: 31 March 2010 / Accepted: 6 May 2010 / Published: 14 May 2010

\begin{abstract}
Plant secondary metabolites include an array of bioactive constituents form both medicinal and food plants able to improve human health. The exposure to these phytochemicals, including phenylpropanoids, isoprenoids and alkaloids, through correct dietary habits, may promote health benefits, protecting against the chronic degenerative disorders mainly seen in Western industrialized countries, such as cancer, cardiovascular and neurodegenerative diseases. In this review, we briefly deal with some plant foods and herbs of traditional medicines and diets, focusing on their neuroprotective active components. Because oxidative stress and neuroinflammation resulting from neuroglial activation, at the level of neurons, microglial cells and astrocytes, are key factors in the etiopathogenesis of both neurodegenerative and neurological diseases, emphasis will be placed on the antioxidant and anti-inflammatory activity exerted by specific molecules present in food plants or in remedies prescribed by herbal medicines.
\end{abstract}

Keywords: Ayurvedic medicine; Mediterranean diet; neurodegenerative diseases; nutritional therapy; phytotherapy; Traditional Chinese Medicine 


\section{Introduction}

Neuroprotection refers to the strategies and relative mechanisms able to defend the central nervous system (CNS) against neuronal injury due to both acute (e.g. stroke or trauma) and chronic neurodegenerative disorders (e.g. Alzheimer's disease, AD, and Parkinson's disease, PD). Among these strategies, herbal medicine may represent a valuable resource in prevention rather than in therapy of some CNS diseases, in association with a healthy lifestyle including correct dietary habits and moderate physical activity. As complementary and alternative therapy, herbal medicine, or simply phytotherapy, refers to the medical use of plant organs (leaves, stems, roots, flowers, fruits and seeds) for their curative properties. Generally, herbal products contain complex mixtures of active components (phytochemicals), including phenylpropanoids, isoprenoids and alkaloids, and it is often difficult to determine which component(s) of the herb(s) has biological activity [1-4].

Nutritional therapy is a healing system using functional foods and nutraceuticals as therapeutics. This complementary therapy is based on the assumption that food is not only a source of nutrients and energy, but can also provide health benefits. In particular, the reported health-promoting effects of plant foods and beverages can be ascribed to the numerous bioactive chemicals present in plant tissues and, consequently, occurring in foods. Consumed as part of a normal diet, plant foods are thus not only a source of nutrients and energy, but may additionally provide health benefits beyond basic nutritional functions, by virtue of their dietary therapeutics (phytochemicals) [5-8].

In this survey, we briefly introduce neurodegenerative diseases, $\mathrm{AD}$ and $\mathrm{PD}$ in particular, with emphasis on the preventive strategies represented by herbal medicine and nutritional therapy. We provide an ethnobiological approach, focusing on plant foods and medicinal herbs used by different traditional medicines and diets and relevant for some of their neuroprotective components.

\section{Neurodegenerative diseases}

A neurodegenerative disease is defined as a deterioration, often irreversible, of the intellectual and cognitive faculties and it is generally associated with ageing and/or AD, PD, stroke.

\subsection{Ageing and oxidative stress}

With the increase of ageing population, neurological diseases represent a relevant health problem. Sensu lato, an age-dependent degenerative disorder represents a condition in which the function and/or structure of affected tissues or organs experience progressively deterioration over time, such as cardiovascular and neurodegenerative diseases, immune system (immunosenescence) and skeleton muscle decline (sarcopenia). Ageing is a complex physiological process that involves both morphological and biochemical changes occurring, with the passage of time, in single cells and the whole organism. Among the many theories proposed to explain the mechanisms of ageing at the molecular level, the oxidative stress or free radical hypothesis has received wide support. At biochemical level, oxidative stress can be defined as a disturbance in the cell oxidation/reduction (redox) status, leading to the production of partially reduced oxygen intermediates, more reactive than molecular oxygen in its ground state, including both radical and nonradical forms collectively termed as reactive oxygen species (ROS). Therefore, ROS production and oxidative damage to 
biomacromolecules (nucleic acids, lipids and proteins) can represent a suitable environment for the development of age-related diseases [9].

Neurodegeneration is a process involved in both neuropathological conditions and brain ageing. Although the brain accounts for less than $2 \%$ of the body weight, it consumes about $20 \%$ of the oxygen available through respiration. Therefore, because of its high oxygen demand, the brain is the most susceptible organ to oxidative damage [10-12]. Additionally, the high amount of polyunsaturated fatty acids (PUFAs) present in neuronal membranes makes the brain tissues particularly susceptible to lipid peroxidation reactions, resulting in the formation of cytotoxic aldehydes, such as malondialdhyde (MDA) and 4-hydroxynonenal (HNE) [13].

To protect vulnerable targets, organisms have evolved sophisticated strategies, collectively termed antioxidant defences, that counteract the imbalance of the cell redox homeostasis and keep the ROS levels under the cytotoxic threshold [14]. Antioxidant defences also comprise (plant) vitamins and phytochemicals, i.e. nonenzymatic scavengers abundant in food and medicinal plants and introduced by diets [15-18]. Any compound capable of quenching ROS, without itself undergoing conversion to a destructive radical species, can be considered as an antioxidant, as in the case of dietary phytochemicals $[19,20]$.

\subsection{Alzheimer's (AD) and Parkinson's (PD) diseases}

Amongst a variety of neurodegenerative diseases, Alzheimer's disease is the most prevalent and devastating disorder and the first cause of institutionalisation in the elderly population. Clinical signs of $\mathrm{AD}$ are characterized by progressive and irreversible memory deficits, cognitive deterioration and personality changes, usually with an onset after 65 years of age. Memory impairment appears in the early stage of the disease, and motor and sensory functions are not affected until later stages. Parkinson's disease is the second most common ageing-related neurodegenerative diseases that can greatly impair quality of life. As opposed to cognitive deficits of $\mathrm{AD}, \mathrm{PD}$ is a movement disorder, whose classical signs include resting tremors, bradykinesia, extrapyramidal rigidity and loss of postural reflexes such as disturbance in walking or equilibrium. The consequence of these diseases are also very significant in terms of the cost of caring for patients [21,22].

\subsubsection{Epidemiology of AD and PD}

Incidence rates of neurodegenerative diseases such as AD and PD increase exponentially with age. According to the World Health Organization (WHO), neurodegenerative diseases will become the world's second leading cause of death by the middle of the century, overtaking cancer [23]. In 2000, there were 4.5 million Americans diagnosed with $\mathrm{AD}$, with an annual estimated cost of $\$ 100$ billion [24]. Presently, it is predicted that by 2050 the number of AD patients in the US population could range from 11 to 16 million if no cure or preventive measure is found [25]. AD is the most common cause of dementia in the elderly and accounts for $60-80 \%$ of cases. According to the Global Burden of Disease Study, dementia and other neurodegenerative disorders will be, by 2020, the eighth cause of disease burden for developed regions [26]. In Europe, AD shows a prevalence of $0.4 \%$ in women and $0.3 \%$ in men aged $60-69$ years [27]. 
PD affects approximately $1 \%$ of population aged 65-69 years and the prevalence increases to $3 \%$ in the 80 year old or above group [28]. Its incidence is approximately 1.5 times higher in men than woman at all ages [29]. It is estimated that in Western Europe, by 2030, the number of PD cases will double from 4.5 to 9 million [30]. The prevalence of PD varies in different ethnic and geographic groups [31]. For instance, a north-south geographic gradient has been observed for PD, with prevalence increasing with latitude in both hemispheres, as compared with the equatorial zones. Furthermore, white populations appear more at risk than black subjects [32].

\subsubsection{Neuropathology of $A D$ and $P D$}

Although AD and PD largely differ in their clinical symptoms and disease course, both disorders are basically provoked by a progressive loss of neurons in different neuronal systems. Furthermore, as for most neurodegenerative diseases, they are characterized by the aggregation of intracellular proteins [33]. The presence of extracellular senile plaques and intracellular accumulation of neurofibrillary tangles (NFTs) in brain tissues of affected patients have been identified as histopathologic alterations of AD. Senile plaques are composed of fibrillar amyloid (A ) peptides produced by cleavage of the A precursor protein (APP), whereas NFTs consist of hyperphosphorylated microtubule associated tau protein $(\mathrm{P})$. Selective neuronal loss is particularly severe in specific cerebral areas: the neocortex, hippocampus, limbic system and subcortical areas [34].

PD is characterized by the selective degeneration of dapaminergic neurons located in the pars compacta of the substantia nigra. One of the main neuropathological hallmarks of PD is the aggregation of the intracellular protein -synuclein, to form intracytoplasmic inclusions (Lewy bodies) in these neurons [35].

\subsubsection{Etiopathogenesis of $\mathrm{AD}$ and $\mathrm{PD}$}

The etiology of neurodegenerative diseases is multifactorial, with a complex combination of genetic and non-genetic components. Most neurodegenerative diseases occur sporadically, arising from the interaction among environmental factors and genetic susceptibility. Only a small minority of cases are of purely genetic origin, due to a mutation of genes encoding for the abnormally aggregating proteins [36]. Age is the only reliable risk factor for the sporadic forms, differently from familial forms that can exceptionally affect young subjects [37].

Currently, oxidative damage is believed to be one of the leading cause of neuronal degeneration in both AD and PD [38-42]. Though the exact mechanisms of AD are still unknown, several lines of evidence suggest that oxidative stress is implicated in A -induced neurotoxicity, besides apoptosis and inflammation, two processes strictly related to ROS overproduction [43-45]. Moreover, the aggregation and toxicity of the A peptides involve transition metals. Data suggest a close relationship between cerebral biometal $(\mathrm{Fe}, \mathrm{Cu}, \mathrm{Zn}$ ) deregulation and $\mathrm{AD}$ pathology, with redox-active metals and A peptides that interact to elevate oxidative stress in brain tissues [46,47]. Mitochondria, a main source of ROS since their aerobic metabolism, represent a main biochemical target of AD. Damaged mitochondria are less efficient producers of energy in form of ATP and more efficient producers of ROS, thus exacerbating oxidative stress [48]. 
In PD, all the mechanisms involved in selective degeneration of dopaminergic neurons in the nigrostriatal system are still unknown, though evidence suggests the involvement of ROS. Oxidative stress may arise from the metabolism of dopamine with the production of potentially harmful free radical species [49]. Compared to the rest of brain, the subtantia nigra pars compacta is exposed to a higher rate of ROS formation and to higher levels of oxidative stress. The reason for this is not clear yet, but may be related to the energy metabolism of these cells or to their high content of dopamine [50].

\subsubsection{Current pharmacological intervention for $\mathrm{AD}$ and $\mathrm{PD}$}

There is no cure for neurological diseases and only symptomatic treatments are available. Current therapies for $\mathrm{AD}$ and $\mathrm{PD}$ mainly provide symptomatic improvement by replacing the levels or controlling the metabolism of neurotransmitters involved in the diseases, to restore their imbalance. Cholinesterase inhibitors are the earliest developed and still the first line prescript drug available for patients with mild to moderate AD. By inhibiting the hydrolysis of acetylcholine in the synaptic cleft, these drugs restore the levels of the neurotransmitter in the affected neurons of AD patients $[51,52]$. For moderate to severe cases, memantine has been approved. This drug acts as a specific, noncompetitive $\mathrm{N}$-methyl-D-aspartate (NMDA) receptor antagonist able to counteract the excitotoxicity of glutamate, the major excitatory neurotransmitter in the brain [53,54]. Anti-inflammatory and antioxidant therapies have been also proposed as possible preventive strategies, though, at present, conclusive data are not available $[55,56]$.

Current therapeutic approach for the symptomatic treatment of PD includes levodopa (L-DOPA) as the most effective drug. After administration, levodopa is converted to dopamine, thus replenishing the diminished dopamine levels in affected tissues [57,58].

\subsection{Acute cerebrovascular attack (stroke)}

This is an ischemia (a reduction or a blockage of oxygen and glucose supply) generally caused by thrombosis or haemorrhage which blocks the blood flow to a specific brain region. In particular, the occlusion of a cerebral vessel due to a blood clot (thrombus) discharged from the surface of an atherosclerotic lesion may cause an ischemic stroke, whereas an intracranial or intracerebral haemorrhage, commonly caused by hypertension, may lead to a haemorrhagic stroke $[59,60]$.

Stroke is currently the second leading cause of death in industrialized countries, ranking after heart disease and before cancer, and a major cause of permanent disability [61]. Interestingly, about $25 \%$ of patients develop dementia within three months after a stroke $[62,63]$. In fact, both A and APP are deposited in cortical and subcortical brain areas of non-dementia patients following stroke [64].

\section{Traditional Chinese Medicine}

Traditional Chinese Medicine (TCM) is one of the world's oldest documented medical systems based on herbal medicines. It has been estimated that about $20 \%$ of the plant species listed in Flora Sinica are used as medicaments [65]. Typical TCM concepts are Yin, Yang and Qi, components of 'vital energy' difficult to translate into Western medical terms. Unlike the concept adopted in Western 
medicine, 'vital energy' in TCM is a term for collectively describing both the mental and physical energy. It is believed to be essential for growth, daily activities, reproduction, cognitive functions and unbalance of Yin and Yang breaks body's harmony predisposing to diseases. To restore this harmony is the principle for treating illnesses. In Chinese tradition, ageing is considered a progressive decline of vital energy in our body, and anti-ageing herbs are able to correct the imbalance of vital energy components [66,67]. In the ancient TCM book 'Yellow Emperor's Canon of Internal Medicine', appropriate lifestyles are described to preserve vital energy in our body, such as optimal diet, moderate exercise and reduction of both mental and physical stress, able to increase lifespan beyond 100 years of age [68]. According to the tradition, the Yellow Emperor established herbal medicine about 5,500 years ago, assaying hundreds of plants to discover medicinal herbs [69]. Despite the completely different basic philosophical principles, the ancient, but still vital, TCM has represented a therapeutic wisdom for Western medicine in recent years, as in case of anti-ageing herbs [70]. In the following section, Ginkgo biloba L., Panax ginseng C.A. Mayer and Scutellaria baicalensis Georgi, herbs mostly involved in neuroprotection, will be briefly described.

\subsection{Ginkgo biloba L. (Yín Xìng or Yín Hsìng)}

From the Chinese term Ginkyo meaning silver apricot, due to its yellow seeds, it is a tall and ancient tree (Figure 1a) with a remarkable long life span of more than 4,000 years due, at least in part, to its high tolerance to abiotic/environmental stresses and resistance to pathogen infections. This species, belonging to the Ginkgoaceae family, is considered a 'living fossil' because of its primitive characters and absence of close living relatives [71]. The medical use of this plant can be traced back to approximately 5,000 years to the origins of TCM. Modern Chinese pharmacopoeia introduced Ginkgo leaves, typically fan-shaped (Figure 1b), as treatment for vascular insufficiency and to improve longevity, whereas seeds are used as astringent for the lung to treat illnesses like asthma and chronic bronchitis [72].

Figure 1. Ginkgo biloba L. tree (a) and its typical fan-shaped leaves (b).
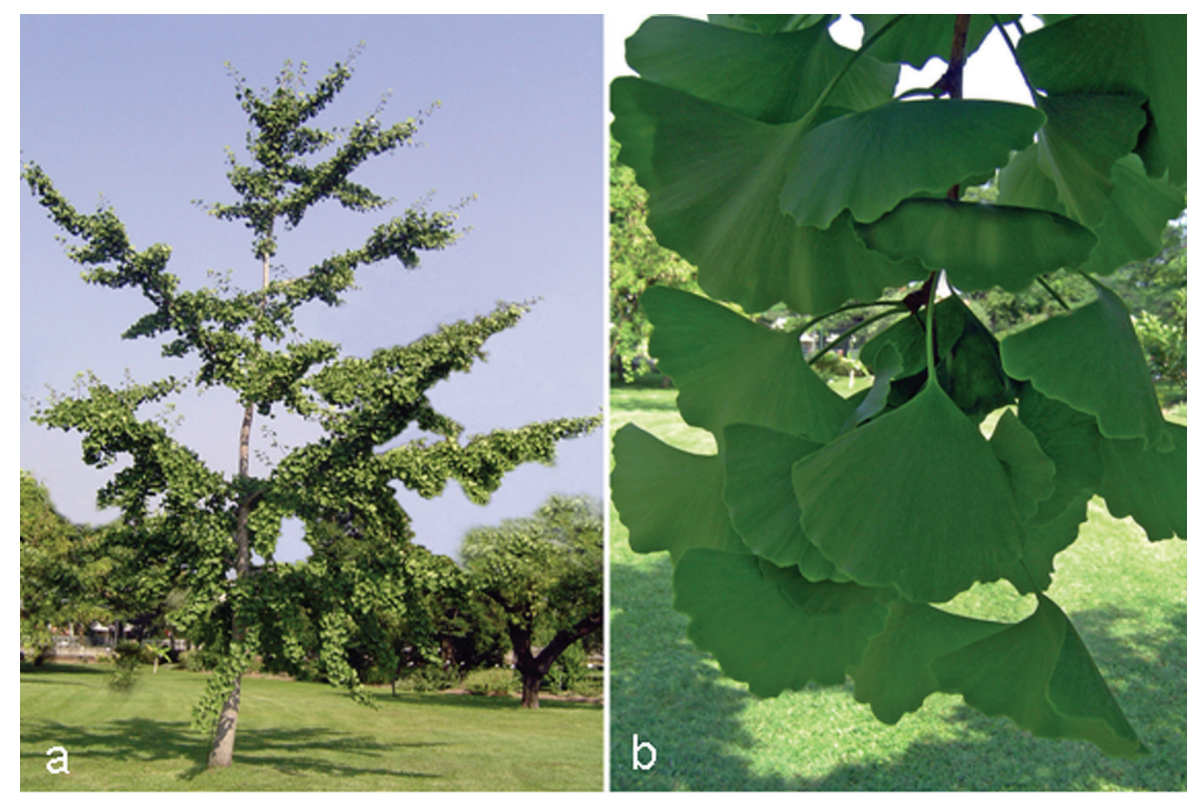
Since 1965, German physicians have prescribed G. biloba for the treatment of cognitive dysfunction, dementia and AD. In the early 1970s, the standardized extract of G. biloba leaves (EGb 761) was registered and, since then, patented products were developed and commercialized [73]. Presently, standardized extracts are widely prescribed in Europe and US for the symptomatic treatment of $\mathrm{AD}$ and cerebral insufficiency (a nonspecific age-related deterioration of mental functions), and for the improvement of cerebral blood flow and memory [74]. EGb 761 contains 24\% of flavonoids and $6 \%$ of terpenic lactones, giving this extract its unique polyvalent pharmacological action. The flavonoid fraction is mainly composed of three flavonols, quercetin, keampferol and isorhamnetin, whereas terpenic derivatives are represented by diterpenic lactones, the ginkgolides $\mathrm{A}, \mathrm{B}, \mathrm{C}, \mathrm{J}$ and $\mathrm{M}$, and a sesquiterpenic trilactone, the bilobalide (Figure 2) [74]. Ginkgolides are antagonist of plateletactivating factor (PAF), able to reduce platelet activation and aggregation, thus improving blood circulation [75]. Bilobalide can reduce damage caused by global brain ischemia and excitotoxicityinduced neuronal death [76].

Figure 2. Main flavonoids (quercetin, kaempferol and isorhamnetin), ginkgolides (A, B, C, J, M) and bilobalide of Ginkgo biloba L.

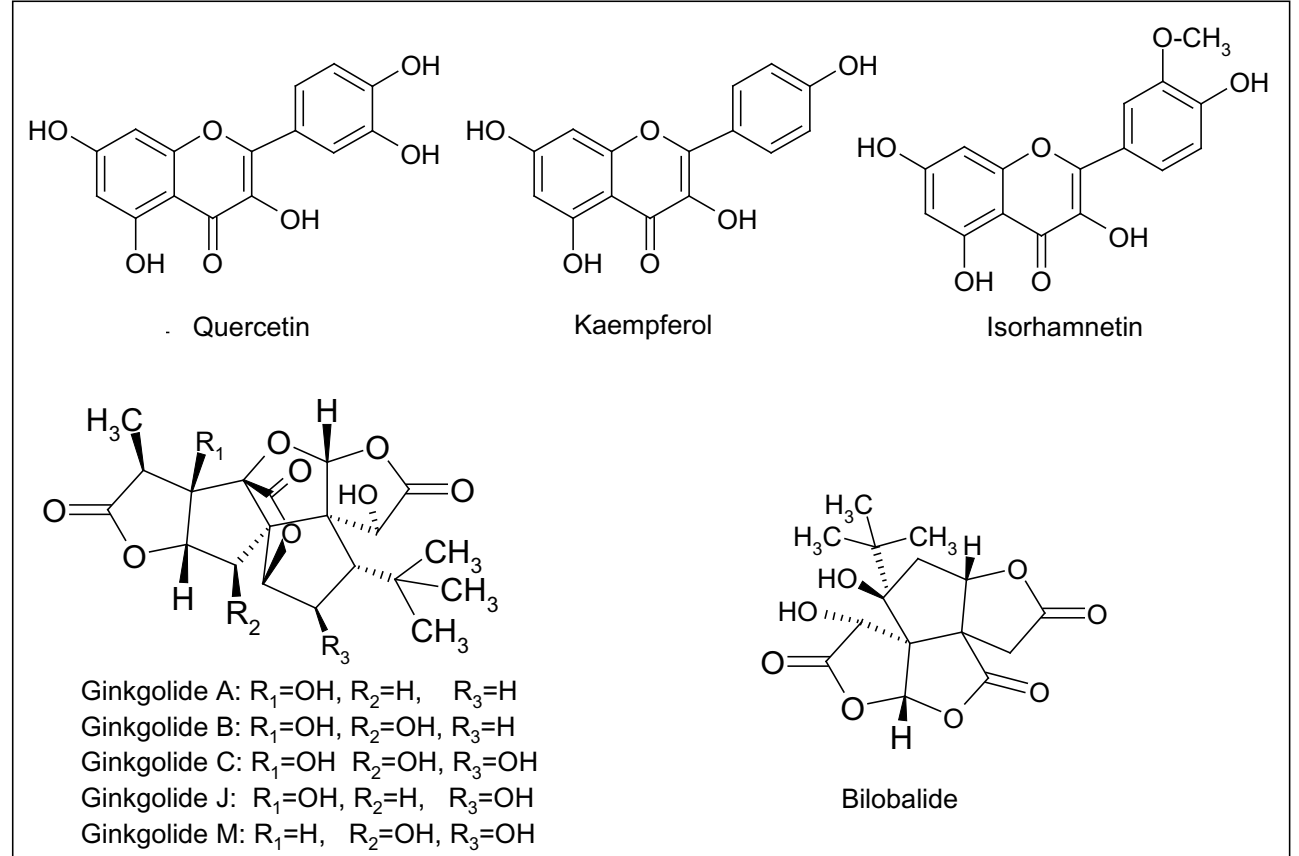

In general, the neuroprotection exerted by EGb 761 is due to the combination of antioxidative, antiamyloidogenic and antiapoptotic activities, by virtue of the blend of its bioactive phytochemicals [77-81]. The efficacy of EGb 761 has been assessed by different clinical studies. In a randomized, double blind, placebo-controlled trial, patients of the treatment groups received over a 24-week period an oral daily dose of $160 \mathrm{mg}$ EGb 761 or $5 \mathrm{mg}$ donepezil (a cholinesterase inhibitor), whereas the control group was treated with a placebo. According to the primary outcome measures (Syndrome Kurz Test, SKT, Mini-Mental State Examination, MMSE, and Clinical Global Impression, CGI), the study showed that both EGb 761 and donepezil were more effective than the placebo in improving the cognitive function of patients with mild to moderate $\mathrm{AD}$, whereas no statistical difference was reported between treatments [82]. In a meta-analysis reviewing many randomized, double blind, placebo- 
controlled clinical studies, patients diagnosed with $\mathrm{AD}$ received 120 to $240 \mathrm{mg}$ /day of EGb 761 for 3 to 6 months. A standardized neuropsychological scale, the Alzheimer's Disease Assessment Scale Cognitive subscale (ADAS-Cog), was used to evaluate the efficacy of treatment on cognitive function. It was observed a modest, but significant, effect translated into 3\% improvement on the primary outcome (ADAS-Cog) in treatment group [83]. Similar results were reported later in a cohort of woman aged 75 years and older [84]. Currently, two phase III clinical trials, the GEM (Ginkgo Evaluation of Memory) study in US and the GuidAge study in France, focus on the evaluation of EGb 761 efficacy in the prevention of $\mathrm{AD}$ in more than 3,000 patients/study older than 70 years. Both studies were randomized, double blind, placebo-controlled trials [85,86]. In GEM study, EGb 761 was administered in a dose of $120 \mathrm{mg}$ twice daily and the incidence of all-cause dementia was used as primary outcome. Secondary outcome included the rate of cognitive decline, the incidence of cardioand cerebrovascular events and mortality [85,87]. In GuidAge study, the efficacy of $240 \mathrm{mg}$ daily of $\mathrm{EGb} 761$ was evaluated, with the incidence of $\mathrm{AD}$ during a 5-year follow up period as primary outcome [87]. The latter study is the largest clinical trial carried out in Europe on the prevention of AD and its final results will be available in 2010 [87].

\subsection{Panax ginseng C.A. Mayer}

Ginseng (from the Chinese rènsh $n=$ man root, which refers to the root shape resembling the leg of a man), one of the most widely used herbs in TCM for boosting Qi (energy), is another anti-ageing herbs, employed for thousands of years as a tonic and revitalizing agent [88]. Ginseng refers to a group of several species within the Panax (from the Greek pan = all, and akèia = cure) genus and the family of Araliaceae growing in north-eastern Asia, with $P$. ginseng (Figure 3a), or Asian ginseng, among the most commonly used species also in Korean traditional medicine and Kampo (Japanese traditional medicine). Other important species are Vietnamese ginseng (P. vietnamensis Ha et Grushv.), Siberian ginseng (Eleutherococcus senticosus Maxim., which is not a true ginseng) and American ginseng ( $P$. quinquefolius L.) [89].

Figure 3. Panax ginseng C.A. Meyer: aerial parts (a) and root (b).

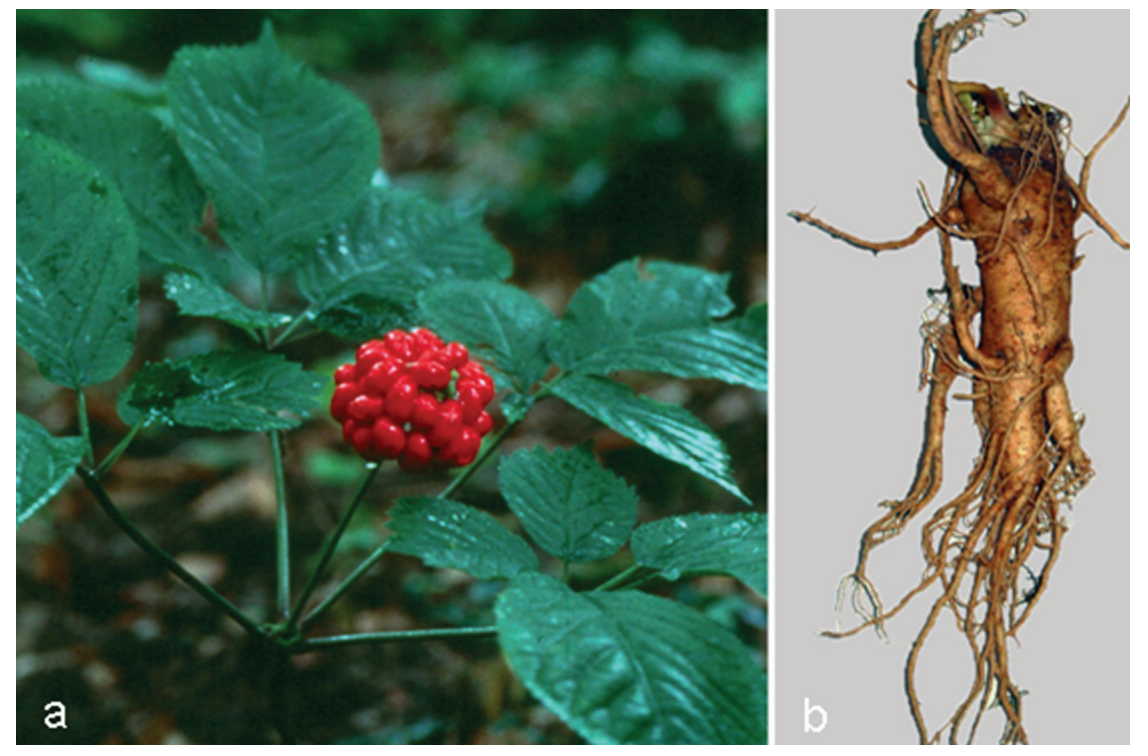


Ginseng root (Figure 3b), characterized by the presence of ginsenosides (triterpenic saponin complexes) (Figure 4), is considered an adaptogenic herb, able to increase the body's resistance to stress, trauma, anxiety and fatigue by modulating the immune function. Furthermore, it improves memory, learning performance, motor activity and, as aphrodisiac, ginseng can be applied to patients with sexual dysfunction. Depending on their aglycone, ginsenosides are often divided into two groups: $\mathrm{Rb} 1$ group ( $\mathrm{Rb} 1, \mathrm{Rb} 2, \mathrm{Rc}$ and $\mathrm{Rd}$ ) and $\mathrm{Rg} 1$ group (Re, $\mathrm{Rf}, \mathrm{Rg} 1$ and $\mathrm{Rg} 2$ ), characterized by the presence of protopanaxadiol and propanaxatriol, respectively (Figure 4) [90-92].

Figure 4. Ginsenosides of Panax ginseng C.A. Meyer root; Rb1 and Rg1 are characterized by different aglycones, protopanaxadiol and propanaxatriol, respectively.

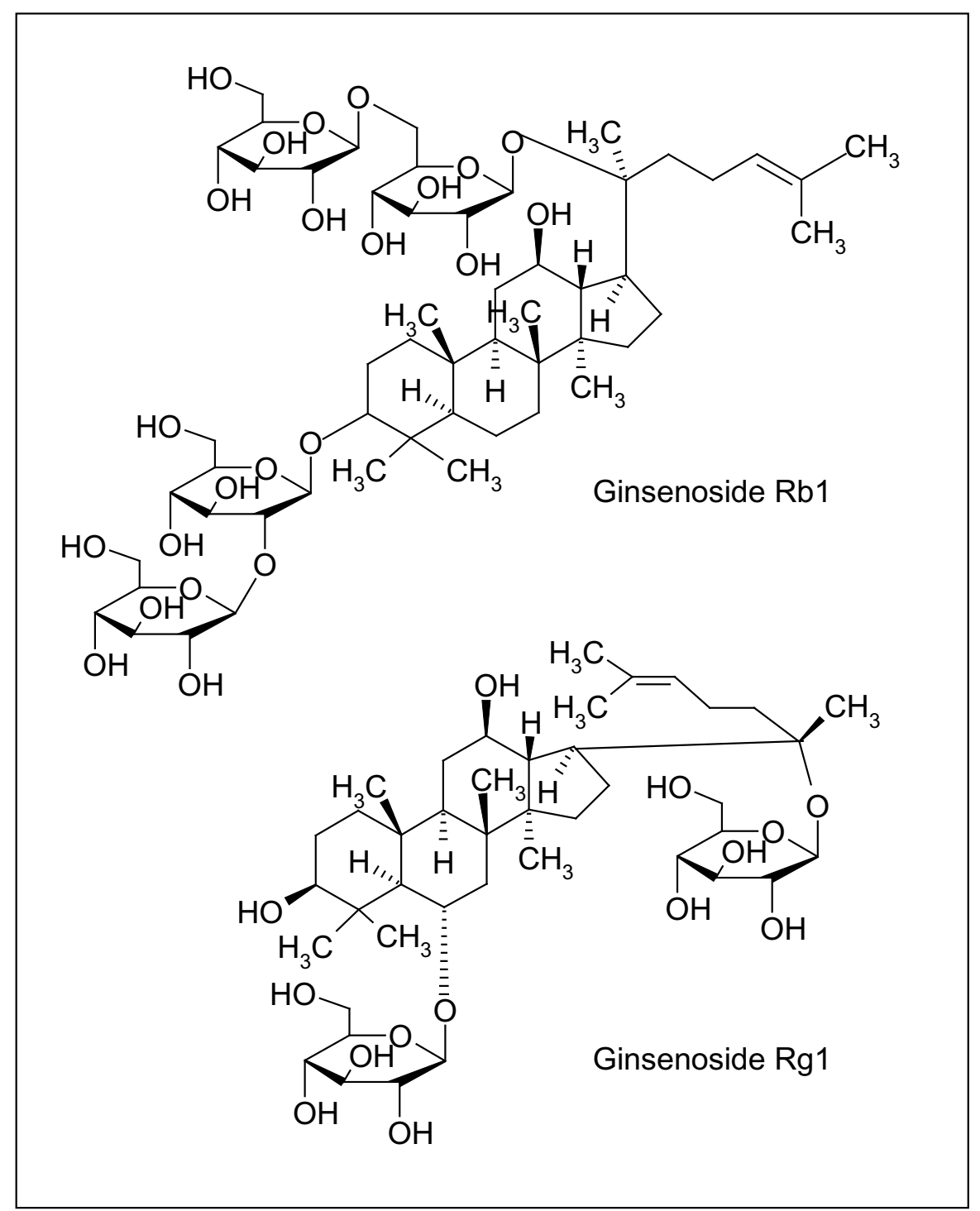

Ginseng may provide protection against neurodegeneration by multiple mechanisms. In different experimental models of $\mathrm{AD}$, it attenuates $\mathrm{A}$ - and glutamate-induced toxicity, enhances clearance of A by stimulating the phagocytic activity of microglia and promotes neuron survival, increasing the levels of neurotrophic factors [93-97]. These data show that ginseng components act on different 
stages of the neurodegenerative disease, thus suggesting that multi-target properties are optimal for a neuroprotective herb.

Human studies have investigated the efficacy of ginseng too. In a clinical trial, patients aged 50 years or older with mild to moderate $\mathrm{AD}$ dementia were randomized into three groups. Two treatment groups received an oral daily dose of 9 or $4.5 \mathrm{~g}$ of Korean red ginseng (similar to Chinese ginseng) for 12 weeks. The primary outcome measures were MMSE, ADAS and Clinical Dementia Rating (CDR). The high-dose ginseng group showed scores of the outcome measures significantly higher than the control group ones. Differences between low-dose ginseng and placebo were not significant [98].

Apart from $\mathrm{AD}$, ginseng has shown protective effects against PD in several cell culture and animal models. Both ginsenosides and root extracts are able to promote neuronal cell survival by reducing the neurotoxicity induced by toxins or parkinsonism mimetics, such as 1-methyl-4-phenyl-1,2,3,6-tetrahydropyridine (MPTP) and its active metabolite 1-methyl-4-phenylpyridinium (MPP+) in rodents. These neurotoxins induce oxidative stress and lead to cell death of dopaminergic neurons, as in PD [99-101]. In other studies, ginsenosides, besides protecting neuronal cells, have shown neurotrophic effects promoting neurite overgrowth [102,103].

\subsection{Scutellaria baicalensis Georgi (Huáng Qín)}

This is a medicinal plant (Figure 5) belonging to the Lamiaceae family and widely used in the oriental (Korean and Chinese) traditional medicine because of its powerful anti-inflammatory and antioxidant activity.

Figure 5. Scutellaria baicalensis Georgi aerial parts.

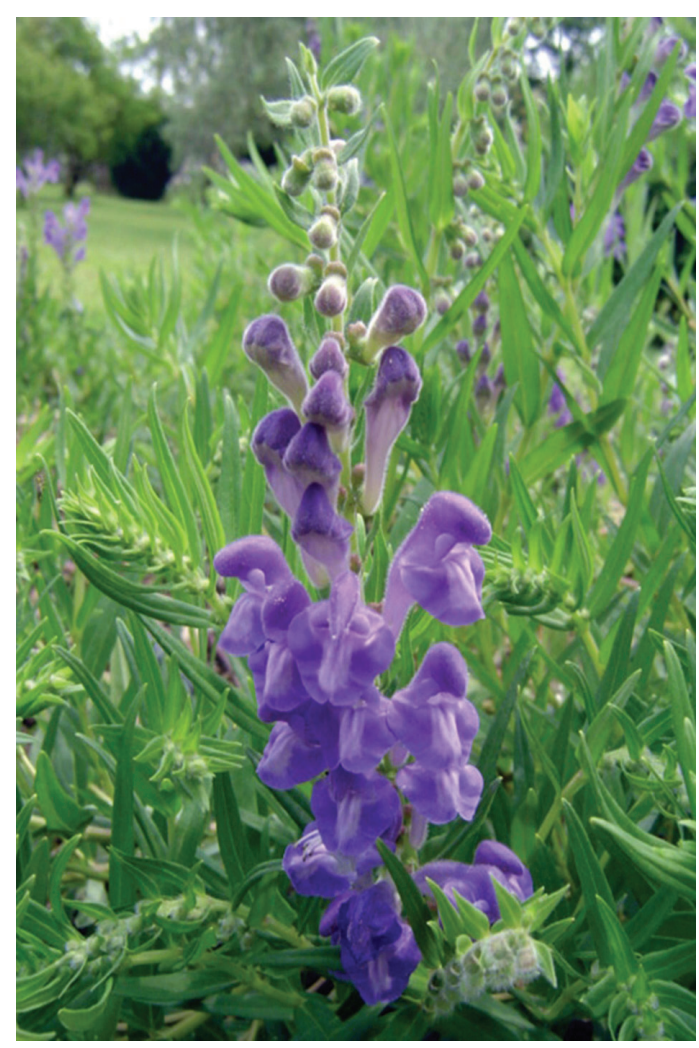


In Korea, a root extract rich in bioactive components is used to treat diverse (neuro)inflammatory diseases [104-107]. In CNS, neuroglia plays a critical role in inflammation. Upon inflammatory stimulus (infection, trauma or other), microglial cells, the resident immune effectors (the counterpart of monocytes/macrophages in the periphery), migrate to the site of damaged tissue to defend the organism. In some cases, if their defence responses are not tightly regulated, they may further injury the host tissue by (over)producing ROS and releasing inflammatory mediators, such as cytokines and eicosanoids. Similarly, proliferation and activation astrocytes, a population of glial cells which provide mechanic and metabolic support to neurons, may exacerbate these neurotoxic effects in the inflammation environment [108-110].

Three main flavonoids, baicalein (5,6,7-trihydroxyflavone), baicalin (baicalein 7-O-glucuronide) and wogonin (5,7-dihydroxy-8-methoxyflavone) (Figure 6), isolated from the root have been assayed for numerous potential benefits [111]. As antioxidant agents, in different cell culture and animal models, these compounds showed to quench ROS, to protect neurons from oxidative damage in cerebral ischemia/reperfusion (I/R) injury, to inhibit lipid peroxidation of neuronal membranes and to prevent excitotoxicity induced by glutamate [112-121].

Figure 6. Main flavonoids isolated from Scutellaria baicalensis Georgi root.

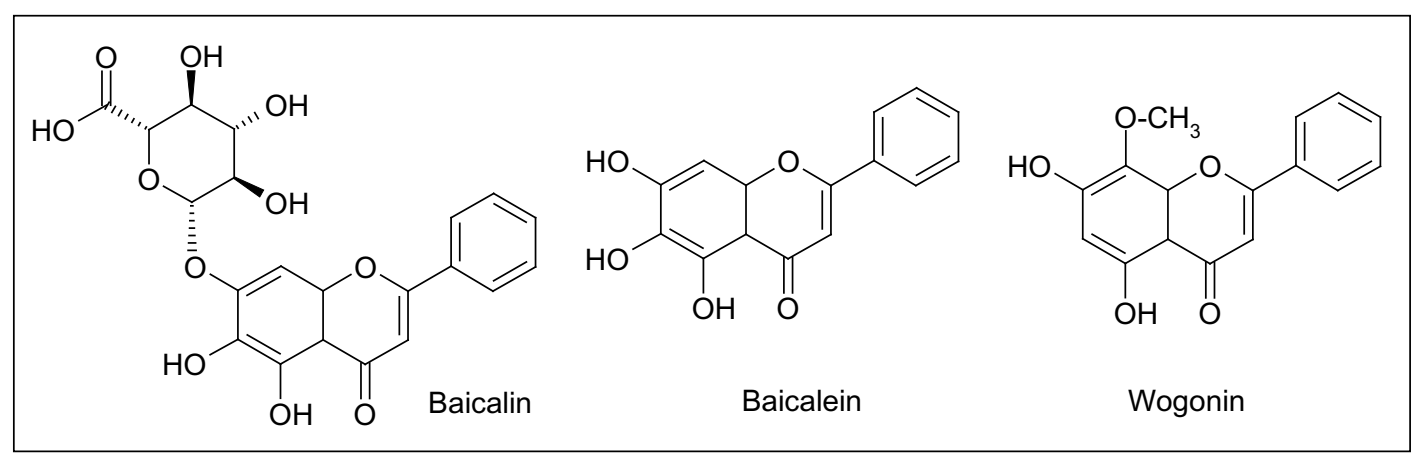

As an inhibitor of inflammation in the CNS, wogonin suppressed both NO (nitric oxide, a reactive nitrogen species able to increase the cell oxidative burden) production and inducible nitric oxide synthase (iNOS) activation in cultured rat astrocytes [122]. The same S. baicalensis metabolite inhibited the inflammatory cascade, in LPS-stimulated, cultured microglia cells, by the suppression of cytokines, such as TNF (tumor necrosis factor)- and IL (interleukin)-1 , and of the pro-inflammatory transcription factor NF(nuclear factor)- B $[119,123]$. NF- B is widely expressed in tissues of nervous system. It resides in the cytoplasm as inactive form which translocates to the nucleus upon activation. In neurons, NF- B is activated by various stimuli, such as cytokines, neurotrophic factors, neurotransmitters, and, once in the nucleus, it binds to specific DNA consensus sequences, regulating the transcription of genes involved in immune and inflammatory responses [124]. Inhibition of inflammatory activation of microglia by wogonin reduced cytotoxicity towards co-cultured PC12 neurons, supporting an in vitro neuroprotective role of this flavonoid. The efficacy of wogonin was further demonstrated in two experimental brain injury models. In the 4-vessel occlusion model of transient global ischemia, wogonin decreased the death rate of hippocampal neurons, the induction of iNOS and TNF- in hippocampus, whereas, in the kainate injection model, this flavonoid markedly 
protected from excitotoxic brain injury [119]. Similarly, baicalein attenuated the NO production by suppressing iNOS induction, in LPS-activated BV-2 mouse microglial cells, besides reducing apoptotic cell death and NF- B activation [107]. Finally, baicalein and baicalin protected neurons from A -induced toxicity, inhibited fibrillation of -synuclein and disaggregates existing fibrils [125-127].

The amount of baicalin in Scutellaria is approximately 10-fold that of baicalein. After oral administration of the aqueous extract of $S$. baicalensis, baicalein, baicalin and wogonin are rapidly absorbed. Baicalin is metabolized into baicalein by bacteria prior to intestinal absorption, the latter metabolite being detected in plasma up to $24 \mathrm{~h}$. In rat, baicalein enters brain crossing BBB and distributes in cortex, hippocampus, striatum, thalamus and brain stem in 20 minutes [128-131].

\section{Ayurvedic Medicine}

Ayurveda is a very ancient and complex knowledge system including philosophy, religion and science (medicine) applied to daily life. It is based on three fundamental principles or doshas, vata, pitta and kapha, that regulate all cellular processes responsible for healthy life. Vata governs movements and activities, pitta the heath and energy levels, whereas kapha regulates growth and structural modification. When these principles get disturbed, because of unfavourable environment or poor diet, the individual starts suffering from some diseases [132]. In India, the history of medicine can be traced to the remote past, with one of the earliest mention of medicinal use of plants reported in Rig Veda, a sacred collection of Sanskrit hymns written between 4,500 and 1,600 BC [133]. Since antiquity, Ayurveda is practiced through its eight specialized branches: Kayachikitsa (internal medicine), Salya (surgery), Salakya (ophtalmology and ENT), Kaumarbhritya (pediatrics), Aagada (toxicology), Bhuta Vidya (psychology), Rasayana (rejuvenation) and Bajikarana (or Vajikarana, sexology) [134]. Among these disciplines, Rasayana tantra regards the treatments to improve longevity, memory, to attain youthful appearance, to maintain cognitive performance and physique strength. As for TCM, Ayurveda is not only a collection of herbal therapies, but a regimen covering the general mode of life: social conduct, behaviour and diet. In particular, the rejuvenation therapy prescribed by Rasayana should begin in adult life or midlife because it could not be effective when started to late, thus pointing out the preventive rather than curative efficacy of this approach [134]. Interestingly, some Rasayana preparations directly refer to dementia and it is remarkable that an ancient healing system has elaborated a theory and a therapy for age-related illnesses, considered as inexplicable phenomenon and attributed to spiritual sphere by contemporary ethnomedical systems. Possibly, the most important plant species in Ayurvedic life style, with reference to neuroprotection, is Curcuma longa L.

\subsection{Curcuma longa $\mathrm{L}$.}

The Curcuma genus belongs to the Zingiberaceae, the same family of Zingiber (ginger). Curcuma longa is a short-stemmed ( $100 \mathrm{~cm}$ in height), perennial plant (Figure 7a) naturally growing throughout the Indian subcontinent and in tropical Asia, particularly in Southeast Asia. Turmeric, the dried ground rhizome of C. longa (Figure 7b), is a spice contained in curry, widely used for its flavouring in many food preparations and recipes. The bright yellow colour of turmeric is due to 
curcumin (Figure 8), the main bioactive constituent and the colouring ingredient present in the powdered rhizome. Many synonyms are known for turmeric: haldi in Hindi, chiang huang in Chinese, ukon in Japanese, haridra or gauri in Sanskrit, kurkum in Arabic [135-137].

Figure 7. Curcuma longa L.: aerial parts (a) and rhizome (b).
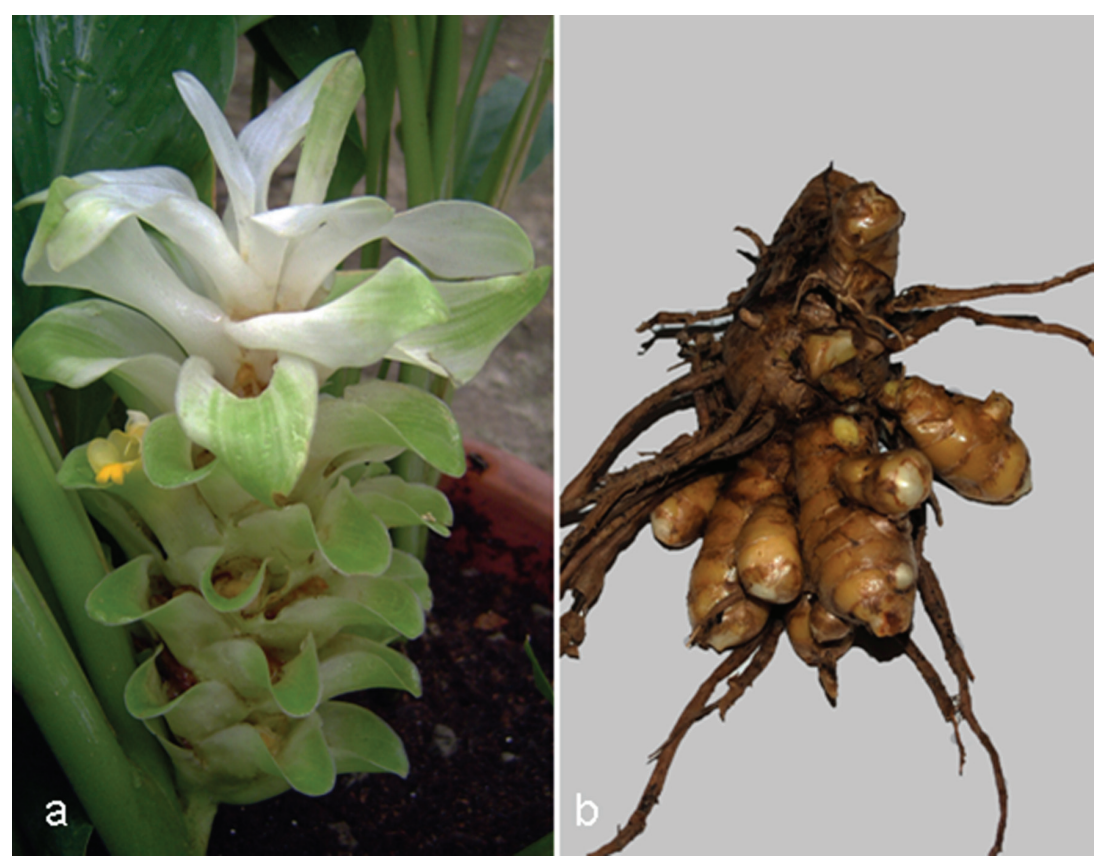

In addition to its applications as spice, dye, food additive and preservative in traditional Indian cookery, turmeric has been used for thousands of years in Ayurvedic and Chinese medicine. In the 12th-13th century, it was introduced, together with other spices, to Western countries by Arab traders and Marco Polo, after they visited India. Currently, turmeric continues to be widely used as an alternative medicinal agent in many parts of southern and eastern Asia, where it is considered as a 'blood purifier', for the treatment of common ailments such as dyspepsia, flatulence, liver disorders, arthritis, urinary tract diseases, wounds, jaundice, eye infections and skin diseases such as acnes and pemphigus [135-137].

Figure 8. Curcuminoids, polyphenolic constituents of turmeric, the dried ground rhizome of Curcuma longa L.

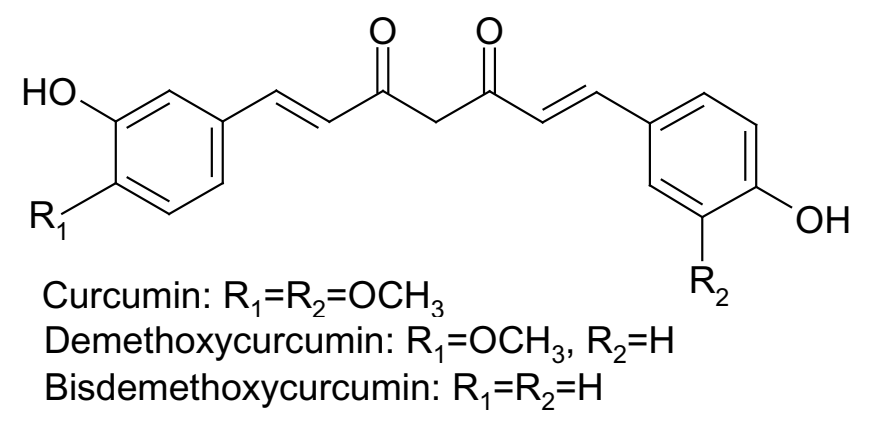


The most bioactive chemical constituents of turmeric are curcuminoids, a group of polyphenols including mainly curcumin, demethoxycurcumin and bisdemethoxycurcumin (Figure 8). Components of turmeric are currently undergoing scientific evaluation for numerous potential benefits due to their anti-inflammatory, antiproliferative, pro-apoptotic, antioxidant, antiviral and antidiabetic activity. Numerous molecular targets of curcumin have been identified over the years, including cyclooxygenase (COX)-2 and lipoxygenase (LOX) [135-137].

Epidemiological studies have raised the hypothesis that the wide use of Curcuma among Indians may explain the significantly lower prevalence of AD in India compared to US [138]. In a transgenic animal model of $\mathrm{AD}$, supplementation with a low dose of curcumin (160 ppm), for six months, reduced indices of both inflammation and oxidative stress. In particular, the levels of proinflammatory cytokine IL-1, of oxidised proteins and of A peptide decreased significantly [139]. Antiamyloidogenic activity of curcumin was extensively reported in in vitro and animal models [140-144]. The binding to the redox-active metals iron and copper suggest another neuroprotective mechanism induced by curcumin, at least in animals [145]. The combination of nonsteroidal anti-inflammatory drugs (NSADs) and curcumin attenuated oxidative damage, cognitive deterioration and A peptide deposition in both cell culture and animal model,. In the same study, anti-inflammatory activity of curcumin was observed, due to the inhibition of cytokine production and microglia activation and to the increase of phagocytosis index [146]. Because the process of inflammation plays a major (detrimental) role in the pathogenesis of the most chronic illnesses, including neurodegenerative diseases, the therapeutic potential of curcumin as anti-inflammatory agent in the prevention and treatment of chronic disorders has been recently highlighted [147]. In fact, as previously introduced, activation of microglial cells in CNS results in the production of pro-inflammatory mediators that propagate neuronal injury exacerbating neurodegenerative diseases. In rat, curcuminoid pigments suppressed NO production by LPS-activated microglia [148]. In a model of global cerebral ischemia, induced in Mongolian gerbils by transient occlusion of common carotid arteries, administration of curcumin by intraperitoneal injections ( $30 \mathrm{mg} / \mathrm{kg}$ body weight) for two months attenuated ischemiainduced neuronal death and glial activation. The decrease of lipid peroxidation, mitochondrial dysfunction and apoptotic indices were other biochemical responses mediated by curcumin. Cerebral $\mathrm{I} / \mathrm{R}$ injury was also ameliorated, as shown by the locomotor activity of treated animals after I/R. Finally, bioavailability experiments reported a rapid increase of curcumin in plasma and brain tissues within 1 hour after administration [149].

\section{Mediterranean Traditional Diets}

In the Mediterranean basin, different traditional dietary patterns have developed in each geographical subarea (southern Italy and France, Spain, Greece, Turkey, Northern Africa and Middle East), and, hence, a unique Mediterranean diet does not really exist. Traditionally, these dietary habits originated in areas where olive (Olea europaea L.) and grapevine (Vitis vinifera L.) (Figure 9a,b) were cultivated, olive oil and wine produced and regularly consumed [150]. Besides these foodstuffs, other main components of Mediterranean diets include whole grains, fruits, vegetables, legumes, nuts, yogurt and ricotta as dairy products, fish and white meat as protein sources [151]. Nowadays, Mediterranean diets, rich in fruits and vegetables, are correlated to a low incidence of the chronic- 
degenerative disorders mostly spread in western populations, and compelling evidences point out the reduced risk of cancer, cardiovascular and neurodegenerative diseases in Mediterranean populations, compared with other industrialized countries [152-154].

Figure 9. Traditional Mediterranean cultivations: Olea europea L. (a) and Vitis vinifera L. (b).
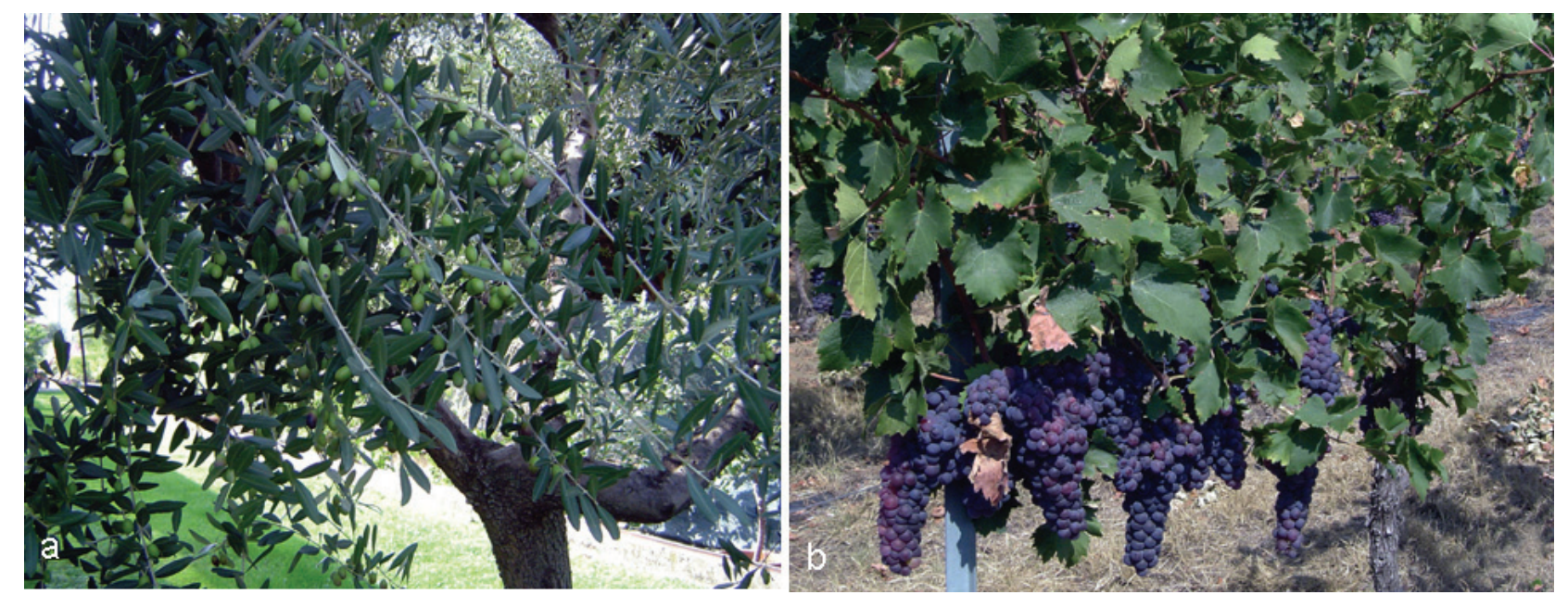

\subsection{Grape (Vitis vinifera L.) and red wine}

As attested by Theophrastus and Hesiod, viticulture and winemaking were extensively practiced in ancient Greece, though it is widely believed that both these practices began earlier, in the Neolithic Period (8,500-4,000 BC). Besides religious, social and academic (at the symposium) contexts wherein wine was introduced, its medical uses were studied by Greek physicians, as reported by Hippocrates' studies (460-370 BC). He recommended wine to cure fever and as analgesic, antiseptic, diuretic, tonic and digestive [155]. The Romans also attributed therapeutic properties to wine, and Galen (129-200 $\mathrm{AD}$ ), in particular, provided a detailed description on the medical uses of wine in his practice. In the care of gladiators, he used wine as antiseptic for wound healing and as analgesic for surgery. Other illnesses that Roman physicians treated by wine included depression, memory loss, constipation, diarrhoea, gout, halitosis, snakebites, tapeworms, urinary tract ailments and vertigo [156].

Grape/wine chemistry is quite complex, and, in berry, bioactive secondary metabolites are mainly distributed in epidermal (skin) tissues and seeds. Phytochemicals include plenylpropanoids, isoprenoids (responsible for the wine flavouring) and alkaloids (such as indolic compounds), whose amount and variety in planta strictly depend on genetic, environmental and agricultural factors [157]. Though the great diversity of molecules present in grape, polyphenols represent the archetype of the health-promoting effects arising from a regular, moderate wine consumption, as attested, in the last decades, by the great amount of studies focusing on the biological activity of particular grape polyphenols, such as the stilbene resveratrol and flavonoids (Figure 10) [158,159].

As recently reviewed, many prospective, population-based cohort and case control studies have provided the substantial evidence that a regular (daily or possibly 3-4 times weekly) intake of moderate amounts ( 2 glasses/days) of red wine, at meals and in the context of a Mediterranean dietary style, is associated with a lower risk of developing dementia and AD [160]. In particular, the largest metaanalysis on alcohol consumption and risk of dementia suggested that low to moderate wine drinking 
significantly reduced by 38 and $32 \%$ the risk of dementia and AD, respectively [161]. However, it has been suggested the hypothesis that the drinker and not the drink may produce benefits, because of the healthier life-style habits of wine drinkers in relation to their beer-, spirit-drinking and abstention counterparts. Wine drinkers are more often women, college graduates, non-smokers who perform a moderate physical activity [162,163]. In any case, immoderate or excessive consumption of wine and/or other alcoholic beverages is associated with an increased risk of dementia, possibly due to the neurotoxicity of ethanol or resulting from the concomitant malnutrition/nutrition deficiency [164]. In the Copenhagen City Hearth Study, wine intake on a monthly, weekly or daily basis was associated with a lower risk of stroke, compared with no wine intake. No association between beer or spirit consumption and risk of stroke was reported, thus suggesting that some wine components, in addition to ethanol, may be responsible for the beneficial effect of wine drinking on the risk of stroke [165]. The Framingham Study evaluated the association between the type of alcoholic beverage and incidence of ischemic stroke, showing a protective effect of wine consumption among subject aged 60-69 years [166]. Results from a case-control study on young women were consistent with the above reported data and, in general, beer and spirit drinking failed to exert neuroprotective effects against ischemic stroke [167]. From the above reported and other studies, the classical J-shaped relationship between alcohol consumption and all-cause mortality could also be extend to the relationship between wine intake and risk of neurodegenerative diseases, besides cardiovascular disorders and cancer $[168,169]$. In J-shaped curve, regular and moderate wine drinking, at the nadir of J, is beneficial, whereas abstinence and heavy intake, on the short and long arm, respectively, are both detrimental, though to a different extent [160].

Figure 10. A stilbene (resveratrol) and a flavonoid (catechin) typically present in grape products.

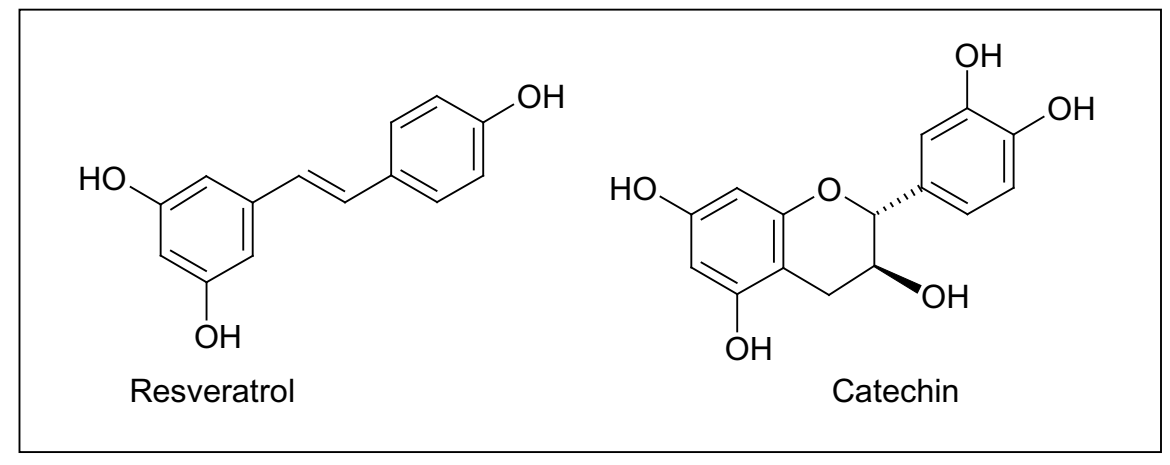

Although association does not imply causality, mechanisms (putatively) involved in wine-induced neuroprotection have been deeply investigated. In general, protective effects of grape polyphenols against neurodegenerative diseases can be ascribed to their anti-amyloidogenic, antioxidant and antiinflammatory activity [170-174]. The daily administration of resveratrol (50 or $100 \mathrm{mg} / \mathrm{kg}$ ) for 1 or 2 weeks to adult male mice significantly prevented the nigrostriatal dopaminergic neuron depletion, after the acute treatment with the neurotoxin MPTP injected itraperitoneally [175]. In different cell lines stably transfected with human APP, resveratrol was shown to promote the intracellular degradation (clearance) of A peptides via a mechanism that involves the proteasome, without direct inhibition of the enzymes - and -secretases implicated in the A protein synthesis [176]. Neuroprotective effects 
of three major grape polyphenolic constituents (resveratrol, quercetin and catechin, Figure 2,10) were assessed in cultured mixed (glial/neuronal) cells of rat hippocampus, as previously introduced a brain area severely affected in both $\mathrm{AD}$ and ischemia. Hippocampal cell treatment with polyphenols reduced the cytotoxicity induced by both the NO free radical donor sodium nitroprusside (SNP) and intracellular ROS accumulation [177]. In a mouse model of $\mathrm{AD}$, the moderate consumption of Cabernet Sauvignon promoted the non-amyloidogenic processing of APP mediated by -secretase, thereby preventing or delaying the generation of A peptides [178]. More recently, a grape seed polyphenolic extract significantly prevented A protein oligomerization, by inhibiting the A protein aggregation into high-molecular-weight oligomeric A species, both in vitro and in Tg2576 mice. Besides, when orally administered to these animals, the extract attenuated the cognitive deterioration typical of AD [179].

Other mechanisms by which polyphenols retard the ageing process and delay the onset of ageingrelated diseases resemble those induced by caloric restriction (CR), suggesting that these compounds and CR share quite similar molecular pathways [180,181]. A moderate reduction in calorie intake of $20-40 \%$ significantly extends lifespan in a wide spectrum of organisms, ranging from bacteria to primates, a process mediated by a family of nicotinamide adenine dinucleotide (NAD+)-dependent deacetylases, the sirtuins (from silent information regulator, SIR, proteins) [182-184]. In mammalians, sirtuins represent novel therapeutic targets to treat age-associated and neurodegenerative diseases, being implicated in a variety of cellular functions, ranging from gene silencing, over the control of cell cycle and apoptosis, to mitochondrial function and energy metabolism [185-187]. Additionally, these proteins play a role in protecting neurons against damage and in prolonging their survival in $A D$ $[188,189]$. Therefore, sirtuin activating compounds (STACs) represent a promising class of therapeutics, including resveratrol, quercetin and other polyphenols able to activate SIRT1. The latter deacetylates both histones and non-histone substrates, such as the tumor suppressor protein p53 and the transcription factor NF-kB, thus regulating some pathophysiological processes affected during ageing and modified by CR [190,191].

\subsection{Salvia officinalis L.}

Salvia is an important genus in the Lamiaceae family consisting of around 900 species, and some species have been cultivated worldwide for medical and culinary uses (Figure 11a,b). Salvia derives from Latin salvus, meaning 'healthy', suggestive of the miraculous therapeutic properties attributed to this plant by traditional medicine, and the textual sources concerning the cultivation and the use of Salvia in the Mediterranean area date back to the ancient Egyptian, Greek and Roman civilizations. Though it is not known which species was used, sage was listed in the Ebers Papyrus (1,500 BC) as a remedy for itching. Followers of Hippocrates praised its styptic and strengthening qualities as well as its beneficial effects on menstruation. Under the name of Salvia, the plant was described in the works of the Romans Plinius, Dioscorides and Galen. They recommended it for warming and contractions, for coughs, hoarseness, for labour pains and ulcers [192]. At the end of 17th century, the physician and botanist Tabernaemontanus recommended many sage preparations from different geographical origins for the treatment of a 'weak brain' and to strengthen memory [2]. 
Figure 11. Salvia officinalis L.: flowers (a) and leaves (b).
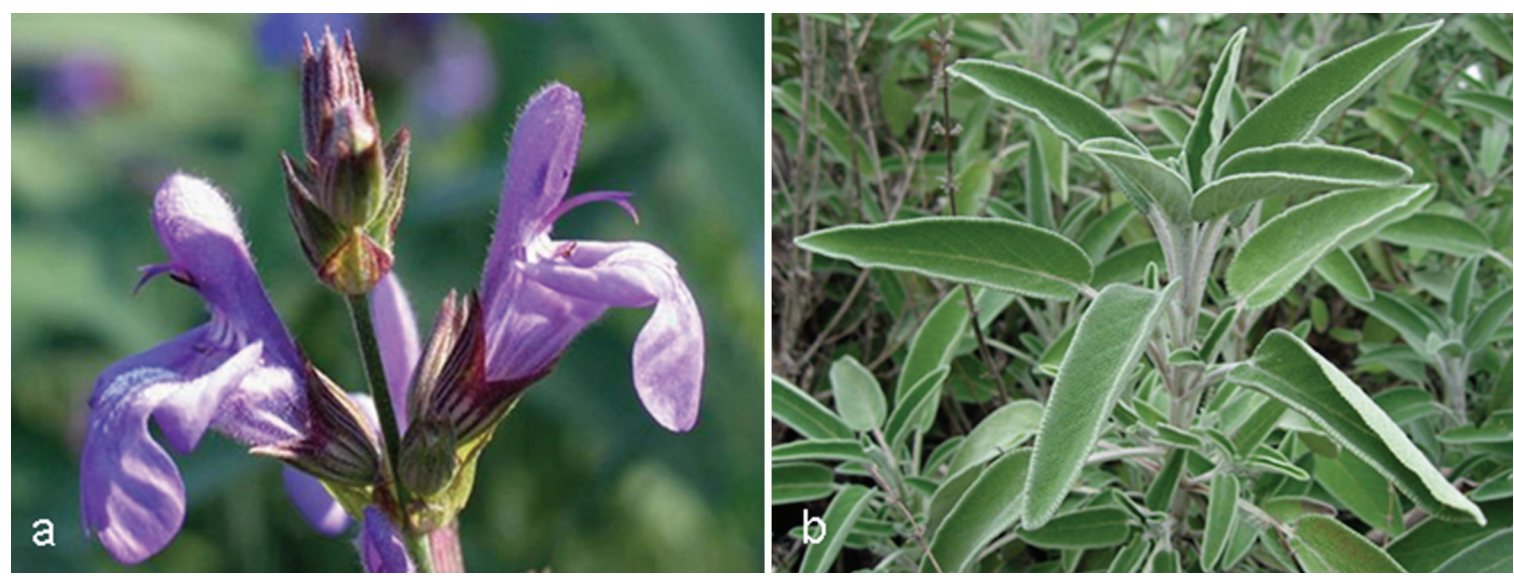

Currently, the health benefits of the Mediterranean diet have also been attributed to the regular consumption of traditional spices, considered as significant sources of bioactive phytochemicals [193-197]. In particular, many pharmacological studies on sage has been performed on volatile constituents (essential oils). The in vitro anticholinesterase activity of $S$. officinalis and $S$. lavandulaefolia (Spanish sage) was reported in both human erythrocytes and brain tissues (postmortem) [198,199]. This activity was attributed to the synergy among monoterpenes present in essential oil, mainly - and -pinene, 1,8-cineole, camphor, borneol, caryophyllene and linalool (Figure 12). Additionally, pure compounds from the extract were tested, none of which fully accounted for the activity of the essential oil [198,200,201].

Figure 12. Main isoprenoids (mono- and sesquiterpenes) present in essential oil extracted from aerial parts of Salvia officinalis L.

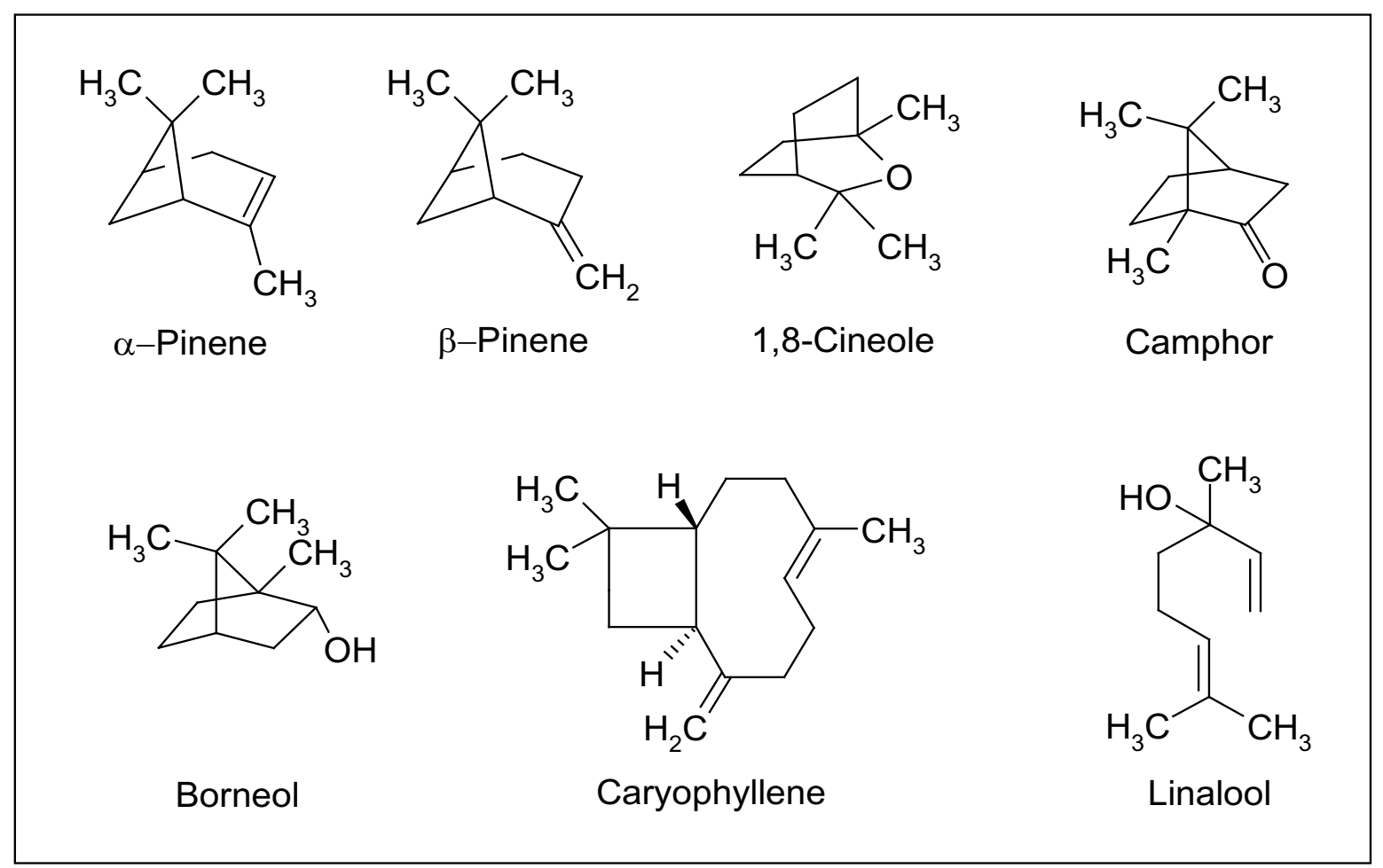


It is noteworthy that the constituents of an essential oil vary within the genotype, geographic distribution and environmental factor. In a clinical trial, a standardized essential oil extract of $S$. lavandulaefolia enhanced memory in young adult volunteers by improving the immediate word recall [199]. The same authors reported that an acute dose of $S$. lavandulaefolia essential oil positively modulated mood and cognitive performance in healthy young adults [202]. Besides inhibition of cholinesterase, other properties of sage essential oil, mainly antioxidant and anti-inflammatory activity, in part due to polyphenols and other phenylpropanoids, are currently considered relevant to the symptomatic treatment of AD [203-205]. In a double blind, randomized, placebo-controlled trial, the efficacy of $S$. officinalis extract was evaluated in patients with mild to moderate AD. After 16 weeks of administration, the treatment group experienced a significantly better outcome on cognitive function than placebo and no difference between the two groups were observed in terms of safety and sideeffects. Though the small number of participants and the relatively short follow up, this clinical investigation suggests that sage may have potential for treatment of AD and related disorders [206].

\section{Two international beverages: coffee and tea}

\subsection{Coffee (Coffea spp.)}

Native to Yemen and Ethiopia, the genus Coffea (Rubiaceae family) includes two main species: $C$. arabica L. (Figure 13), which accounts for most of the world coffee production, and C. canephora $\mathrm{L}$. (syn. C. robusta L.). Coffee is the brewed beverages prepared from roasted seeds, also called coffee beans, the most frequently consumed stimulant drink all over the world. According to 1998 data, the highest annual coffee consumption per capita was observed in Scandinavian countries (greater than $10 \mathrm{~kg}$ of coffee beans), whereas, in US, consumption was about $4.7 \mathrm{~kg} /$ person/year, that is approximately $200 \mathrm{mg}$ of caffeine or two cups of coffee per person per year [207].

Figure 13. Coffea arabica L.: leaves and fruits (coffee cherries).

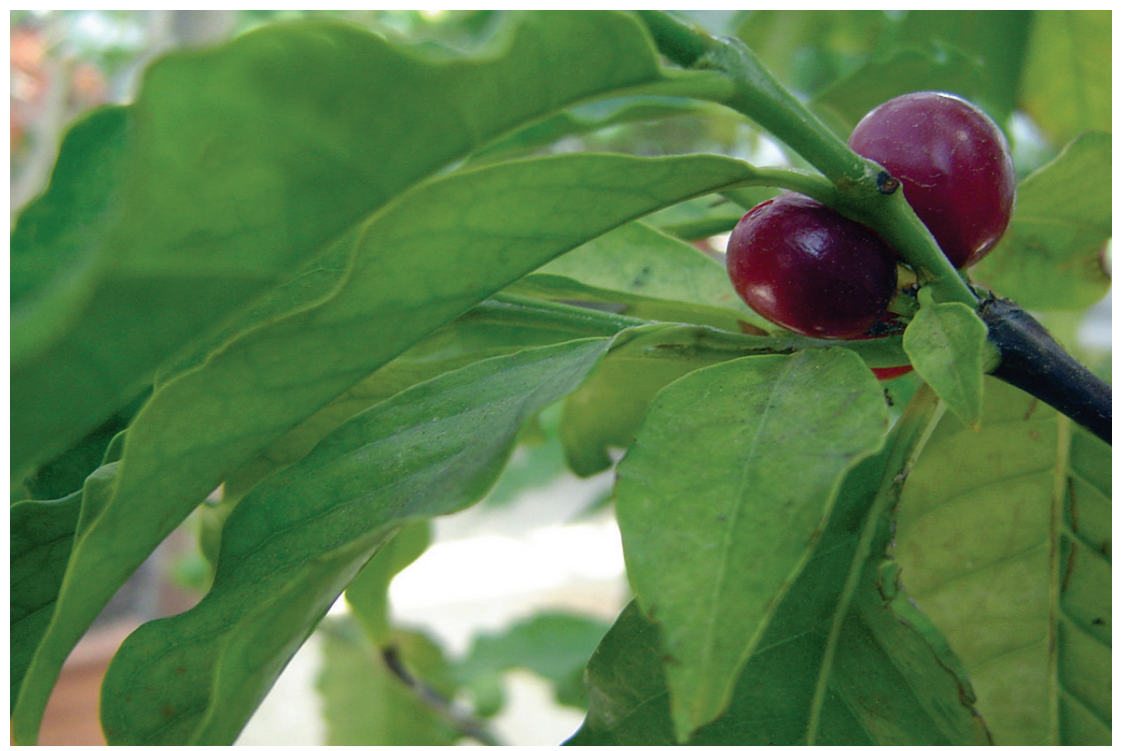


Caffeine, a methylxanthine (Figure 14), is the most important bioactive constituent of this beverage providing neuroprotection. Other structurally similar xanthine alkaloids are theophylline and theobromine (Figure 14), found primarily in tea and chocolate, respectively. Tea is prepared from the leaves of Camellia sinensis Kuntze (Theaceae family), also native to the Old World, whereas cacao derives from the seeds of the New World species Theobroma cacao L. (Sterculiaceae), used by the Aztecs as medicine. These three compounds arise from purine and differ structurally in the number and position of methyl groups: caffeine possesses three groups at positions 1, 3 and 7, whereas theophylline and theobromine are dimethyl xanthine isomers with methyl groups at position 1,3 and 3,7 , respectively (Figure 14). Other important sources of methylxanthine alkaloids are kola nuts (genus Cola, Sterculiaceae family) native to Tropical Africa and used to flavour carbonated beverages, guaraná (genus Paullinia, Sapindaceae) from South America and a popular beverages in Brazil, and Mate (genus Ilex, Aquifoliaceae) native to southern South America and the national drink of Argentina [3].

As regards pharmacological activity, methylxanthines act as adenosine-receptor antagonists. In particular, caffeine is a nonspecific, competitive blocker of adenosine A1 and A2A receptors, distributed throughout the central nervous system [208]. Binding of adenosine to target receptors has general depressant effects, slowing hearth rate and lowering blood pressure. The half-life of caffeine is 3-7 $\mathrm{h}$ in adults and, after ingestion, it is metabolized by the hepatic cytochrome p450 1A2 enzyme into three primary metabolites: paraxanthine (1,7-dimethylxanthine, $c a .80 \%)$, theobromine $(\mathrm{ca} .10 \%)$ and theophylline (ca. 5\%) (Figure 14) [209].

Figure 14. Caffeine and structurally related methylxanthines found primarily in tea (theophylline) and chocolate (theobromine); paraxanthine is the main hepatic metabolite of caffeine after coffee ingestion.

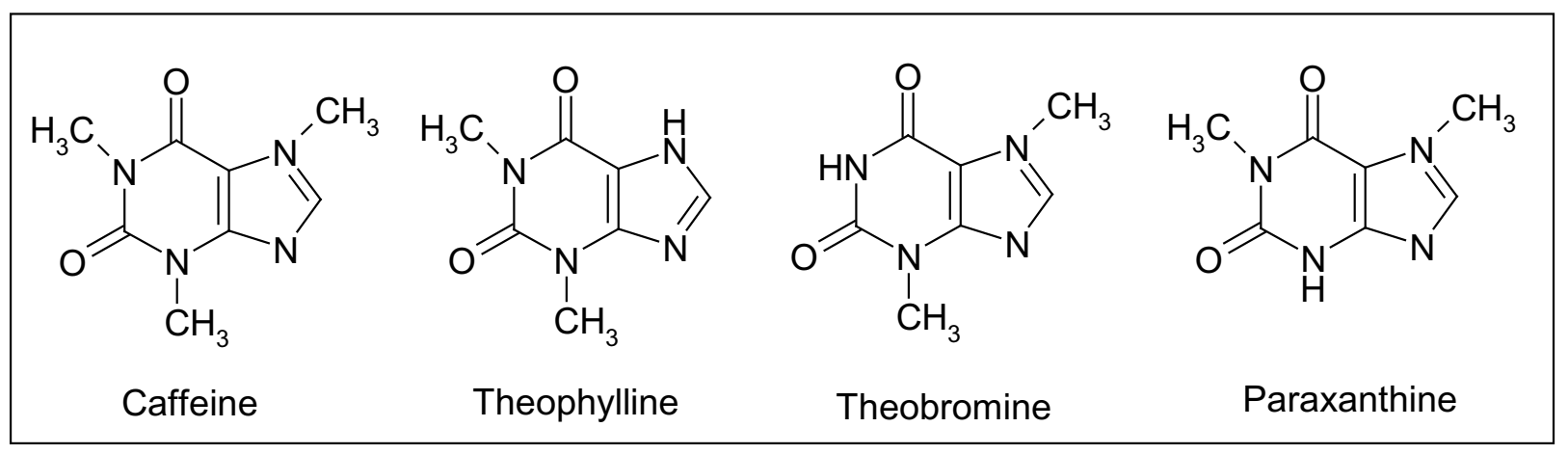

According to human epidemiological studies, caffeine, as well as other adenosine A2A receptor antagonist, may play a role in preventing or delaying the onset of $\mathrm{AD}$. A case control study involving subjects aged 50 years with probable diagnosis of $\mathrm{AD}$ and sex-matched controls found that individuals consuming 2 cups of coffee (approximately $200 \mathrm{mg}$ of caffeine) per day for the previous 20 years were at a significantly lower risk of developing the disease than those that consumed less caffeine [210]. A meta analysis of two case control and two prospective studies examining the effects of coffee on AD also reported that this beverage was protective [211]. In Cancer Prevention Study II Cohort, a prospective study involving more than one million of Americans, coffee intake was reported to be 
inversely associated with PD mortality in men and in women who did not use postmenopausal estrogen therapy [212]. These results were in accordance with previous studies in which coffee consumption was consistently protective against PD for men and women in the absence of estrogen therapy [213,214].

It is noteworthy that acute intake of high doses of coffee ( 5 cups of coffee, approximately $500 \mathrm{mg}$ of caffeine, at one sitting) results in activation of stress responses, as demonstrated by increased plasma levels of cortisol, -endorphin and epinephrine, in turn raising heart rate, blood pressure and releasing free fatty acids from storage [215].

\subsection{Tea (Camellia sinensis Kuntze)}

All tea plants cultivated in different regions of the world belong to the same species, Camellia sinensis Kuntze, though the local growing conditions, (altitude, climate, soils, etc.) may produce numerous distinctive leaves (Figure 15). Nevertheless, the way the leaves are processed is even more important in determining the characteristics of the three predominant types of tea: green, black and oolong. Green tea is the least processed and thus provides the most antioxidant polyphenols, particularly catechins (epigallocatechin, epigallocatechin-3-gallate), flavonols (myricetin, quercetin, kaempherol) and proanthocyanidins [216]. Being catechins (Figure 16), particularly epigallocatechin3-gallate (EGCG), 10-20 times more concentrated than flavonols in normally brewed tea [217], they seem to be responsible for most of the health benefits linked to this beverage. Green tea is made by briefly steaming the freshly harvested leaves, in order to softening them and preventing their fermentation and color changing. After steaming, the leaves are rolled, then spread out and dried with hot air until they are crisp. The resulting greenish-yellow tea has a green, slightly astringent flavor close to the taste of the fresh leaf.

Figure 15. Camellia sinensis Kuntze: leaves and flowers.

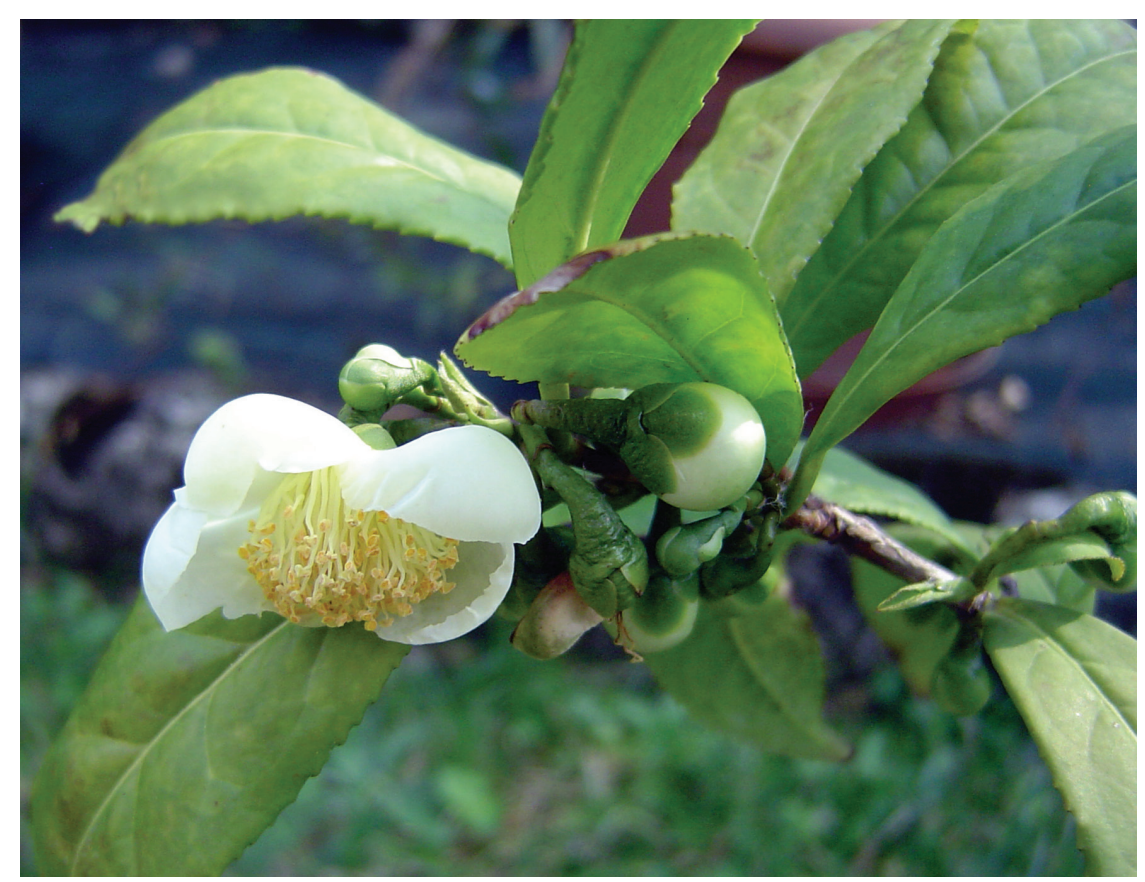


Most of the research showing the health benefits of green tea is based on the amount of green tea typically consumed in Asian countries, that is to say about three cups per day, which would provide 240-320 mg of polyphenols [218-220]. Just one cup of green tea supplies 20-35 mg of EGCG, which has the highest antioxidant activity of all the green tea catechins [216]. Green tea drinkers appear to have lower risk for a wide range of diseases, from simple bacterial or viral infections to chronic degenerative conditions including cardiovascular disease, cancer, stroke, periodontal disease, and osteoporosis [221-230].

Figure 16. Chemical structures of major catechins.

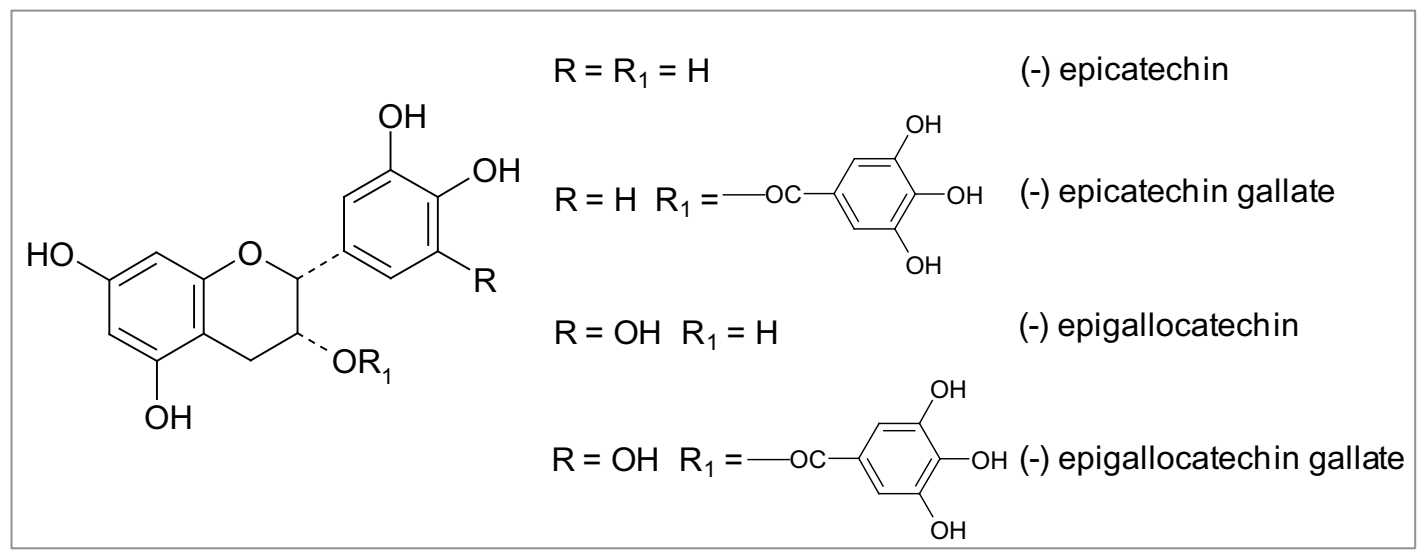

As regards protection against $\mathrm{AD}$ and $\mathrm{PD}$, green tea catechins, until recently thought to work simply as antioxidants, are now known to invoke a wide spectrum of neuroprotective cellular mechanisms. These include iron chelation, scavenging of free radicals, activation of signaling pathways, and regulation of mitochondrial function to avoid excessive production of free radicals [231-233]. As reported above, iron accumulation in specific brain areas and free radical damage to brain cells are considered the major damaging factors responsible for a wide range of neurodegenerative disorders including $\mathrm{AD}$ and $\mathrm{PD}$. In the brain, epigallocatechin-3-gallate (EGCG) has been shown to act as an iron chelator, binding to and removing iron, thus preventing it from contributing to the production of free radicals. In addition to removing iron, EGCG also increases the activity of two major antioxidant enzymes, superoxide dismutase (SOD) and catalase, further helping to decrease free radical damage [233]. Another active compound in green tea, epicatechin (EC) (Figure 16), reduces the formation of -amyloid protein and of the consequent plaque-like deposits in the brain characteristic of AD [77]. The protective effects of black and green tea extracts and their main constituents, epigallocatechin gallate and epicatechin gallate have been shown in an in vitro system of cultured neurons. In presence of these extracts neurons survived to the toxic effect of -amyloid protein [232]. Green tea polyphenols have also demonstrated the ability to affect cell signaling pathways, in particular the MAPK pathways, which are triggered by oxidative stress. MAPK signaling pathways in brain cells are thought to play a critical role in neurodegenerative diseases [231].

Although no human studies on $\mathrm{AD}$ have yet reported benefit from tea consumption, recent population studies have shown that simply consuming two or more cups of green tea daily reduces risk of cognitive decline and PD. In a cohort study at Japan's Tohoku University, using a Mini-Mental State Examination (a well-accepted standardized test for measuring cognitive function) on 1,003 subjects 
over age 70, researchers showed that drinking more than two cups a day of green tea reduces chances of cognitive impairment in both men and women by 64\% [234]. And at every level of cognitive impairment, from minimal to severe, those drinking the most green tea experienced significantly less mental decline than those drinking the least. In particular, compared with elderly Japanese who drank less than three cups a week, those drinking more than two cups a day had a 54\% lower risk of agerelated declines in memory, orientation, ability to follow commands and attention. Those drinking four to six cups of green tea a week (one cup a day) had a 38\% lower risk of declines in brain function [234].

As reported in the previous section, tea contains also caffeine, although half that found in coffee [216]. The amount of caffeine that ends up in a cup of green tea varies according to the amount of tea used and the length of time the leaves are infused [216,217]. Most of the caffeine in green tea is extracted into the water the first time the tea is infused. There is limited research in the published literature comparing the caffeine content of green vs. black tea. A recent study measured the caffeine content in the dry matter of the tea leaves, an approach that allows for control of any confounding variables related to preparation techniques that may impact the caffeine content in the final tea product [216]. This study found that the caffeine content of one gram of black tea ranged from 22-28 milligrams while the caffeine content of one gram of green tea ranged from 11-20 milligrams, reflecting a significant difference. Interestingly, at least two beneficial components in green tea, catechins and the amino acid L-theanine, lessen the impact of its caffeine. When green tea is brewed, its caffeine combines with catechins in the water, reducing the caffeine's activity compared to coffee or cocoa [235]. In addition, L-theanine, which is only found in tea plants and some mushrooms, directly stimulates the production of alpha brain waves, calming the body while promoting a state of relaxed awareness [235].

\section{Conclusions}

Plants, in the form of herbs, spices and foods, constitute an unlimited source of molecules available for improving human health. Nonetheless, a single plant contains hundreds or thousands of secondary, bioactive metabolites, a chemical diversity that determined the evolutionary success of plants, favouring their adaptation to a changing environment [216]. In this view, to ascribe the healthpromoting effects of a medicinal herb or a plant food only to a molecule, or a single class of compounds, represents an inappropriate and inopportune task. It is likely that different phytochemicals produce in vivo additive and/or synergistic effects, thus amplifying (or reducing/inhibiting) their activities.

As implicitly outlined in this survey, most of our current knowledge about CNS-active plants of cultural and traditional importance arose from ethnobotanical and ethnopharmaceutical (including historical) studies, as for other natural active ingredients. Some famous examples include Atropa belladonna L. and Hyoscyamus niger L. from Eurasia for atropine and hyoscyamine respectively, Erythroxylum coca Lam. from Central America for cocaine, Papaver somniferum L. for codeine and morphine and Ephedra sinica Stapf. for ephedrine, both from Asia. Therefore, the ethnobiological approach represents a powerful tool for the discovery of new neuroactive natural products from plants used as medicinal herbs, spices or food in different cultural (ethnic) groups. 
A better comprehension of the bioavailability of dietary phytochemicals is critical in order to correctly evaluate their bioactivity, to interpret the experimental results and to design new approaches, particularly in CNS. However, biokinetic data supporting their absorption, distribution, metabolism and excretion in human body are still fragmentary, despite the enormous amount of indications on their bioactivities. Dietary phytochemicals have to be absorbed to exert their health benefits, and human studies indeed reported the direct evidence of the absorption and urinary excretion of these compounds after the intake. Moreover, for a suitable neuroprotective agent, a very important property regards its ability to cross the blood-brain barrier (BBB), in order to reach the target sites of the CNS. A limited number of studies, both in vitro and on animal models, focused on the ability of flavonoids to cross the endothelial cell layer of BBB, depending on the compound lipophilicity and on the activity of specific transporters [217-222]. It has been suggested that polyphenols may interact with plasma membrane transporters or receptors, triggering downstream intracellular signaling pathways. At present, only a receptor for EGCG has been identified on vascular cells [223]. Nevertheless, the high variability of the data concerning the bioavailability, at least for polyphenols, depends on the complexity of food matrixes (fruits and vegetables) and on the chemical structure of the specific compounds [224-226].

Finally, though the presence of receptors or transporters for polyphenols or other phytochemicals in brain tissues remains to be ascertained, compounds with multiple targets appear as a potential and promising class of therapeutics for the treatment of diseases with a multifactorial etiology [227-229].

\section{Acknowledgements}

We are indebted to Cristina Puricelli for her help in manuscript preparation.

\section{References and Notes}

1. Suk, K. Regulation of neuroinflammation by herbal medicine and its implications for neurodegenerative diseases. A focus on traditional medicines and flavonoids. Neurosignals 2005, 14, 23-33.

2. Adams, M.; Gmünder, F.; Hamburger, M. Plants traditionally used in age related brain disorders a survey of ethnobotanical literature. J. Ethnopharmacol. 2007, 113, 363-381.

3. McClatchey, W.C.; Mahady, G.; Bennett, B.C.; Shiels, L.; Savo, V. Ethnobotany as a pharmacological research tool and recent developments in CNS-active natural products from ethnobotanical sources. Pharmacol. Therapeut. 2009, 12, 239-254.

4. Ho, Y.S.; So, K.F.; Chang, R.C.C. Anti-aging herbal medicine - how and why can they be used in aging-associated neurodegenerative diseases? Ageing Res. Rev. 2010, doi: 10.1016/ j.arr.2009.10.001.

5. Esposito, E.; Rotilio, D.; Di Matteo, V.; Di Giulio, C.; Cacchio, M.; Algeri, S. A review of specific dietary antioxidants and the effects on biochemical mechanisms related to neurodegenerative processes. Neurobiol. Aging 2002, 23,719-35.

6. Aruoma, O.I.; Bahorun, T.; Jen, L.S. Neuroprotection by bioactive components in medicinal and food plant extracts. Rev. Mutat. Res. 2003, 544, 203-215.

7. Ferrari, C.K.B. Functional foods, herbs and neutraceuticals: towards biochemical mechanisms of healthy aging. Biogerontology 2004, 5, 275-289. 
8. Zhao, J. Nutraceuticals, nutritional therapy, phytonutrients and phytotherapy for improvement of human health: a perspective on plant biotechnology application. Rec. Pat. Biotech. 2007, 1, 75-97.

9. Lee, J.; Koo, N.; Min, D.B. Reactive oxygen species, aging, and antioxidant nutraceuticals. Compr. Rev. Food Sci. Food Saf. 2004, 3, 21-33.

10. Halliewll, B. Reactive oxygen species and central nervous systems. J. Neurochem. 1992, 59, 1609-1623.

11. Floyd, R.A. Antioxidants, oxidative stress and degenerative neurological disorders. Proc. Soc. Exp. Biol. Med. 1999, 222, 236-245.

12. Barja, G. Free radicals and aging. Trends Neurosci. 2004, 23, 209-216.

13. Smith, K.J.; Kapoor, R.; Felts, P.A. Demyelination: the role of reactive oxygen and nitrogen species. Brain Pathol. 1999, 9, 69-92.

14. Yu, B.P. Cellular defenses against damage from reactive oxygen species. Physiol. Rev. 1994, 74, 139-162.

15. Cao, G.; Sofic, E.; Prior, R.L. Antioxidant and prooxidant behavior of flavonoids: structureactivity relationships. Free Rad. Biol. Med. 1997, 22, 749-760.

16. Prior, R.L; Cao, G. Antioxidant phytochemicals in fruits and vegetables: diet and health implications. Hortic. Sci. 2000, 35, 588-592.

17. Vinson, J.A.; Yang, J.; Proch, J.; Liang, X. Grape juice, but not orange juice, has in vitro, ex vivo, and in vivo antioxidant properties. J. Med. Food 2000, 3, 167-171.

18. Vinson, J.A.; Teufel, K.; Wu, N. Red wine, dealcoholized red wine, and especially grape juice, inhibit atherosclerosis in a hamster model. Atherosclerosis 2001, 156, 67-72.

19. Bors, W.; Heller, W.; Michel, C.; Saran, M. Flavonoids as antioxidants: determination of radicalscavenging efficiencies. Methods Enzymol. 1990, 186, 343-355.

20. Bors, W.; Michel, C.; Stettmaier, K. Antioxidant effects of flavonoids. Biofactors 1997, 6, 399-402.

21. Pillon, B.; Deweer, B.; Agid, Y.; Dubois, B. Explicit memory in Alzheimer's, Huntington's, and Parkinson's diseases. Arch. Neurol. 1993, 50, 374-379.

22. Paolo, A.M.; Tröster, A.I.; Glatt, S.L.; Hubble, J.P.; Koller, W.C. Differentiation of the dementias of Alzheimer's and Parkinson's disease with the dementia rating scale. J. Geriatr. Psychiatry Neurol. 1995, 8, 184-188.

23. Menken, M.; Munsat, T.L.; Toole, J.F. The global burden of disease study: implications for neurology. Arch. Neurol. 2000, 57, 418-420.

24. Brookmeyer, R.; Gray, S.; Kawas, C. Projections of Alzheimer's disease in the United States and the public health impact of delaying disease onset. Am. J. Public Health 1998, 88, 1337-1342.

25. Hebert, L.E.; Scherr, P.A.; Bienias, J.L.; Bennett, D.A.; Evans, D.A. Alzheimer disease in the US population: prevalence estimates using the 2000 census. Arch. Neurol. 2003, 60, 1119-1122.

26. Murray, C.J.L.; Lopez, A.D. The Global Burden of Disease: A Comprehensive Assessment of Mortality and Disability from Diseases, Injuries, and Risk Factors in 1990 and Projected To 2020; Harvard University Press: Cambridge, USA, 1996.

27. Rocca, W.A.; Hofman, A.; Brayne, C.; Breteler, M.M.B.; Clarke, M.; Copeland, J.R.M.; Dartigues, J.F.; Engedal, K.; Hagnell, O.; Heeren, T.J.; Jonker, C.; Lindesay, J.; Lobo, A.; Mann, 
A.H.; Mölsä, P.K.; Morgan, K.; O’Connor, D.W.; da Silva Droux, A.; Sulkava, R.; Kay, D.W.K.; Amaducci, L. for the EURODEM-Prevalence Research Group. Frequency and distribution of Alzheimer's disease in Europe: a collaborative study of 1980-1990 prevalence findings. Ann. Neurol. 1991, 30, 381-390.

28. Tanner, C.M.; Goldman, S.M. Epidemiology of Parkinson's disease. Neurol. Clin. 1996, 14, $317-335$.

29. Elbaz, A.; Bower, J.H.; Maraganore, D.M.; McDonnell S.K.; Peterson, B.J.; Ahlskog, J.E.; Schaid, D.J.; Rocca, W. A risk tables for parkinsonism and Parkinson's disease. J. Clin. Epidemiol. 2002, 55, 25-31.

30. Dorsey, E.R.; Constantinescu, R.; Thompson, J.P.; Biglan, K.M.; Holloway, R.G.; Kieburtz, K.; Marshall, F.J.; Ravina, B.M.; Schifitto, G.; Siderowf, A.; Tanner, C.M. Projected number of people with Parkinson disease in the most populous nations, 2005 through 2030. Neurology 2007, 68, 384-386.

31. Zhang, Z.X.; Roman, G.C. Worldwide occurrence of Parkinson's disease: an updated review. Neuroepidemiology 1993, 12, 195-208.

32. Emard, J.F.; Thouez, J.P.; Gavreau, D. Neurodegenerative diseases and risk factors: a literature review. Soc. Sci. Med. 1995, 40, 847-858.

33. Shastry, B.S. Neurodegenerative disorders of protein aggregation. Neurochem. Int. 2003, 43, 1-7.

34. Selkoe, D.J. Alzheimer's disease: genes, proteins, and therapy. Physiol. Rev. 2001, 81, 741-766.

35. Agorogiannis, E.I.; Agorogiannis, G.I.; Papadimitriou, A.; Hadjigeorgiou, G.M. Protein misfolding in neurodegenerative diseases. Neuropathol. Appl. Neurobiol. 2004, 30, 215-224.

36. Mayeux, R. Epidemiology of neurodegeneration. Annu. Rev. Neurosci. 2003, 26, 81-104.

37. Elbaz, A.; Dufouil, C.; Alpérovitch, A. Interaction between genes and environment in neurodegenerative diseases. Compte. Rendus Biol. 2007, 330, 318-328.

38. Hunot, S.; Boissiere, F.; Faucheux, B.; Brugg, B.; Mouatt-Prigent, A.; Agid, Y.; Hirsch, E.C. Nitric oxide synthase and neuronal vulnerability in Parkinson's disease. Neuroscience 1996, 72, 355-363.

39. Perry, G.; Taddeo, M.A.; Nunomura, A.; Zhu, X.; Zenteno-Savin, T.; Drew, K.L.; Shimohama, S.; Avila, J.; Castellani, R.J.; Smith, M.A. Comparative biology and pathology of oxidative stress in Alzheimer and other neurodegenerative diseases: beyond damage and response. Comp. Biochem. Physiol. C Toxicol. Pharmacol. 2002, 133, 507-513.

40. Jenner, P. Oxidative stress in Parkinson's disease. Ann. Neurol. 2003, 53, S26-S38.

41. Nikam, S.; Nikam, P.; Ahaley, S.K.; Sontakke, A.V. Oxidative stress in Parkinson's disease. Indian J. Clin. Biochem. 2009, 24, 98-101.

42. Nikam, S.; Nikam, P.; Ahaley, S.K. Role of free radical and antioxidant imbalance in pathogenesis of Parkinson's disease. Biomed. Res. 2009, 20, 55-58.

43. Kaltschmidt, B.; Uherek, M.; Volk, B.; Baeuerle, P.A.; Kaltschmidt, C. Transcription factor NF$\mathrm{kB}$ is activated in primary neurons by amyloid B peptides and in neurons surrounding early plaques from patients with Alzheimer's disease. Proc. Natl. Acad. Sci. USA 1997, 94, 2642-2647.

44. Kaltschmidt, B.; Uherek, M.; Wellmann, H.; Volk, B.; Kaltschmidt, C. Inhibition of NF-kB potentiates amyloid $\beta$-mediated neuronal apoptosis. Proc. Natl. Acad. Sci. USA 1999, 96, 9409-9414. 
45. Kaltschmidt, B.; Heinrich, M.; Kaltschmidt, C. Stimulus-dependent activation of NF-kappaB specifies apoptosis or neuroprotection in cerebellar granule cells. Neuromol. Med. 2002, 2, 299-309.

46. Huang, X.; Atwood, C.S.; Hartshorn, M.A.; Multhaup, G.; Goldstein, L.E.; Scarpa, R.C.; Cuajungco, M.P.; Gray, D.N.; Lim, J.; Moir, R.D.; Tanzi, R.E.; Bush, A.I. The A $\beta$ peptide of Alzheimer's disease directly produces hydrogen peroxide through metal ion reduction. Biochemistry 1999, 38, 7609-7616.

47. Huang, X.; Moir, R.D.; Tanzi, R.E.; Bush, A.I.; Rogers, J.T. Redox-active metals, oxidative stress, and Alzheimer's disease pathology. Ann. NY Acad. Sci. 2004, 1012, 153-163.

48. Zhu, X.; Smith, M.A.; Perry, G.; Aliev, G. Mitochondrial failures in Alzheimer's disease. Am. J. Alzheimers Dis. Other Demen. 2004, 19, 345-352.

49. Jenner, P. Preclinical evidence for neuroprotection with monoamine oxidase-B inhibitors in Parkinson's disease. Neurology 2004, 63, S13-S22.

50. Yuan, H.; Zheng, J.C.; Liu, P.; Zhang, S.F.; Xu, J.Y.; Bai, L.M. Pathogenesis of Parkinson's disease: oxidative stress, environmental impact factors and inflammatory processes. Neurosci. Bull. 2007, 23, 125-130.

51. Klafki, H.W.; Staufenbiel, M.; Kornhuber, J.; Wiltfang, J. Therapeutic approaches to Alzheimer's disease. Brain 2006, 129, 2840-55.

52. Persson, C.M.; Wallin, A.K.; Levander, S.; Minthon, L. Changes in cognitive domains during three years in patients with Alzheimer's disease treated with donepezil. BMC Neurol. 2009, 9, 7.

53. Tariot, P.N.; Farlow, M.R.; Grossberg, G.T.; Graham, S.M.; McDonald S.; Gergel, I. Memantine treatment in patients with moderate to severe Alzheimer disease already receiving donepezil: a randomized controlled trial. JAMA 2004, 291, 317-324.

54. Lleo, A.; Greenberg, S.M.; Growdon, J.H. Current pharmacotherapy for Alzheimer's disease. Annu. Rev. Med. 2006, 57, 513-533.

55. Moore, A.H.; O'Banion, M.K. Neuroinflammation and anti-inflammatory therapy for Alzheimer's disease. Adv. Drug Deliv. Rev. 2002, 54, 1627-1656.

56. Tariot, P.N.; Federoff, H.J. Current treatment for Alzheimer disease and future prospects. Alzheimer Dis. Assoc. Disord. 2003, 17, S105-S113.

57. Lewitt, P.A. Levodopa for the treatment of Parkinson's disease. N. Engl. J. Med. 2008, 359, 2468-2476.

58. Olanow, C.W.; Stern, M.B.; Sethi, K. The scientific and clinical basis for the treatment of Parkinson disease. Neurology 2009, 72, S1-S136.

59. Ginsberg, M.D. Adventures in the pathophysiology of brain ischemia: penumbra, gene expression, neuroprotection: the 2002 Thomas Willis lecture. Stroke 2003, 34, 214-223.

60. Hachinski, V. Stroke and vascular cognitive impairment: a transcisciplinary, translational and transactional approach. Stroke 2007, 38, 1396-1403.

61. Donnan, G.A.; Fisher, M.; Macleod, M.; Davis, S.M. Stroke. Lancet 2008, 371, 1612-1623.

62. Tatemichi, T.K.; Paik, M.; Bagiella, E.; Desmond, D.W.; Stern, Y.; Sano, M.; Hauser, W.A.; Mayeux, R. Risk of dementia after stroke in a hospitalized cohort: results of a longitudinal study. Neurology 1994, 44, 1885-1891. 
63. Tatemichi, T.K.; Desmond, D.W.; Stern, Y.; Paik, M.; Sano, M.; Bagiella, E. Cognitive impairment after stroke: frequency, patterns, and relationship to functional abilities. J. Neurol. Neurosurg. Psychiatry 1994, 57, 202-207.

64. Jendroska, K.; Poewe, W.; Daniel, S.E.; Pluess, J.; Iwerssen-Schmidt, H.; Paulsen, J.; Barthel, S.; Schelosky, L.; Cervos-Navarro, J.; DeArmond, S.J. Ischemic stress induces deposition of amyloid beta immunoreactivity in human brain. Acta Neuropathol. 1995, 90, 461-466.

65. But, P.P.H.; Hu, S.Y.; Kong, Y.C. Vascular plants used in Chinese medicine. Fitoterapia 1980, 3, 245-264.

66. Ody, P. Practical Chinese Medicine: Understanding the Principles and Practice of Traditional Chinese Medicine and Making Them Work for You; Godsfield Press: London, UK, 2000.

67. Ou, B.; Huang, D.; Hampsch-Woodill, M.; Flanagan, J.A. When east meets west: the relationship between yin-yang and antioxidation-oxidation. FASEB J. 2003, 17, 127-129.

68. Wu, L.; Wu, Q.; Wang, B. Yellow Emperor's canon of internal medicine. Zhongguo ke xue ji shu chu ban she : location?1997; pp. 7-8.

69. Zheng, B.C. Shennong's herbal--one of the world's earliest pharmacopoeia. J. Tradit. Chin. Med. 1985, 5, 236.

70. Jiang, W.Y. Therapeutic wisdom in traditional Chinese medicine: a perspective from modern science. Trends Pharmacol. Sci. 2005, 26, 558-563.

71. Zhou, Z.Y.; Zheng, S.L. The missing link of Ginkgo evolution. Nature 2003, 423, 821-822.

72. Fu, L.M.; Li, J.T. A systematic review of single Chinese herbs for Alzheimer's disease treatment. Evid.-Based Complement. Altern. Med. 2009, doi:10.1093/ecam/nep136.

73. Wagner, H. Phytomedicine research in Germany. Environ. Health Perspect. 1999, 107, 779-781.

74. Birks, J.; Grimley, E.J. Ginkgo biloba for cognitive impairment and dementia. Cochrane Database Syst. Rev. 2009, CD003120.

75. Smith, P.F.; Maclennan, K.; Darlington, C.L. The neuroprotective properties of the Ginkgo biloba leaf: a review of the possible relationship to platelet-activating factor (PAF). J. Ethnopharmacol. 1996, 50, 131-139.

76. Chandrasekaran, K.; Mehrabian, Z.; Spinnewyn, B.; Chinopoulos, C.; Drieu, K.; Fiskum, G. Neuroprotective effects of bilobalide, a component of Ginkgo biloba extract (EGb 761) in global brain ischemia and in excitotoxicity-induced neuronal death. Pharmacopsychiatry 2003, 36, S89-S94.

77. Bastianetto, S.; Ramassamy, C.; Doré, S.; Christen, Y.; Poirier, J.; Quirion, R. The ginkgo biloba extract (EGb 761) protects hippocampal neurons against cell death induced by $\beta$-amyloid. Eur. $J$. Neurosci. 2000, 12, 1882-1890.

78. DeFeudis, F.V.; Drieu, K. Ginkgo Biloba extract (EGb 761) and CNS functions basic studies and clinical applications. Curr. Drug Targets 2000, 1, 25-58.

79. Yao, Z.; Drieu, K.; Papadopoulos, V. The Ginkgo biloba extract EGb761 rescues the PC12 neuronal cells from beta-amyloid-induced cell death by inhibiting the formation of beta-amyloidderived diffusible neurotoxic ligands. Brain Res. 2001, 889, 181-190.

80. Gohil, K.; Packer, L. Global gene expression analysis identifies cell and tissue specific actions of Ginkgo biloba extract, EGb 761. Cell. Mol. Biol. 2002, 48, 625-631. 
81. Luo, Y.; Smith, J.; Paramasivam, V.; Burdick, A.; Curry, K.; Buford, J.; Khan, I.; Netzer, W.; Xu, H.; Butko, P. Inhibition of amyloid- $\beta$ aggregation and caspase-3 activation by the Ginkgo biloba extract EGb761. Proc. Natl. Acad. Sci. USA 2002, 99, 12197-12202.

82. Mazza, M.; Capuano, A.; Bria, P.; Mazza, S. Ginkgo biloba and donepezil: a comparison in the treatment of Alzheimer's dementia in a randomized placebo-controlled double-blind study. Eur. J. Neurol. 2006, 13, 981-985.

83. Oken, B.S.; Storzbach, D.M.; Kaye, J.A. The efficacy of Ginkgo biloba on cognitive function in Alzheimer disease. Arch. Neurol. 1998, 55, 1409-1415.

84. Andrieu, S.; Gillette, S.; Amouyal, K.; Nourhashemi, F.; Reynish, E.; Ousset, P.J.; Albarede, J.L.; Vellas, B.; Grandjean, H. Association of Alzheimer's disease onset with Ginkgo biloba and other symptomatic cognitive treatments in a population of women aged 75 years and older from the EPIDOS study. J. Gerontol. A Biol. Sci. Med. Sci. 2003, 58, 372-377.

85. DeKosky, S.T.; Fitzpatrick, A.; Ives, D.G.; Saxton, J.; Williamson, J.; Lopez, O.L.; Burke, G.; Fried, L.; Kuller, L.H.; Robbins, J.; Tracy, R.; Woolard, N.; Dunn, L.; Kronmal, R.; Nahin, R.; Furberg, C. The Ginkgo Evaluation of Memory (GEM) study: design and baseline data of a randomized trial of Ginkgo biloba extract in prevention of dementia. Contemp. Clin. Trials 2006, 27, 238-253.

86. Fitzpatrick, A.L.; Fried, L.P.; Williamson, J.; Crowley, P.; Posey, D.; Kwong, L.; Bonk, J.; Moyer, R.; Chabot, J.; Kidoguchi, L.; Furberg, C.D.; DeKosky, S.T. Recruitment of the elderly into a pharmacologic prevention trial: the Ginkgo evaluation of memory study experience. Contemp. Clin. Trials 2006, 27, 541-553.

87. Vellas, B.; Andrieu, S.; Ousset, P.J.; Ouzid, M.; Mathiex-Fortunet, H. The GuidAge study. Methodological issues. A 5-year double-blind randomized trial of the efficacy of EGb 761® for prevention of Alzheimer disease in patients over 70 with a memory complaint. Neurology 2006, 67, S6-S11.

88. Nocerino, E.; Amato, M.; Izzo, A.A. The aphrodisiac and adaptogenic properties of ginseng. Fitoterapia 2000, 71, S1-S5.

89. Yun, T.K. Brief introduction of Panax ginseng C.A. Meyer. J. Korean Med. Sci. 2001, 16, S3-S5.

90. Tawab, M.A.; Bahr, U.; Karas, M.; Wurglics, M.; Schubert-Zsilavecz, M. Degradation of ginsenosides in humans after oral administration. Drug Metab. Dispos. 2003, 31, 1065-1071.

91. Radad, K.; Gille, G.; Liu, L.; Rausch, W.D. Use of ginseng in medicine with emphasis on neurodegenerative disorders. J. Pharmacol. Sci. 2006, 100, 175-186.

92. Rausch, W.D.; Liu, S.; Gille, G.; Radad, K. Neuroprotective effects of ginsenosides. Acta Neurobiol. Exp. 2006, 66, 369-375.

93. Joo, S.S.; Lee, D.I. Potential effects of microglial activation induced by ginsenoside Rg3 in rat primary culture: enhancement of type a macrophage scavenger receptor expression. Arch. Pharm. Res. 2005, 28, 1164-1169.

94. Chen, F.; Eckman, E.A.; Eckman, C.B. Reductions in levels of the Alzheimer's amyloid $\beta$ peptide after oral administration of ginsenosides. FASEB J. 2006, 20, 1269-71.

95. Li, N.; Liu, B.; Dluzen, D.E.; Jin, Y. Protective effects of ginsenoside Rg2 against glutamateinduced neurotoxicity in PC12 cells. J. Ethnopharmacol. 2007, 111, 458-463. 
96. Joo, S.S.; Yoo, Y.M.; Ahn, B.W.; Nam, S.Y.; Kim, Y.B.; Hwang, K.W.; Lee, D.I. Prevention of inflammation-mediated neurotoxicity by $\mathrm{Rg} 3$ and its role in microglial activation. Biol. Pharm. Bull., 2008, 31, 1392-1396.

97. Shieh, P.C.; Tsao, C.W.; Li, J.S.; Wu, H.T.; Wen, Y.J.; Kou, D.H.; Cheng, J.T. Role of pituitary adenylate cyclase-activating polypeptide (PACAP) in the action of ginsenoside Rh2 against betaamyloid-induced inhibition of rat brain astrocytes. Neurosci. Lett. 2008, 434, 1-5.

98. Heo, J.H.; Lee, S.T.; Chu, K.; Oh, M.J.; Park, H.J.; Shim, J.Y.; Kim, M. An open-label trial of Korean red ginseng as an adjuvant treatment for cognitive impairment in patients with Alzheimer's disease. Eur. J. Neurol. 2008, 15, 865-868.

99. Van Kampen, J.; Robertson, H.; Hagg, T.; Drobitch, R. Neuroprotective actions of the ginseng extract G115 in two rodent models of Parkinson's disease. Exp. Neurol. 2003, 184, 521-529.

100. Chen, X.C.; Zhou, Y.C.; Chen, Y.; Zhu, Y.G.; Fang, F.; Chen, L.M. Ginsenoside Rg1 reduces MPTP-induced substantia nigra neuron loss by suppressing oxidative stress. Acta Pharmacol. Sin. 2005, 26, 56-62.

101. Wang, J.; Xu, H.M.; Yang, H.D.; Du, X.X.; Jiang, H.; Xie, J.X. Rg1 reduces nigral iron levels of MPTP-treated C57BL6 mice by regulating certain iron transport proteins. Neurochem. Int. 2009, $54,43-48$.

102. Rudakewich, M.; Ba, F.; Benishin, C.G. Neurotrophic and neuroprotective actions of ginsenoside Rb1 and Rg1. Planta Med. 2001, 67, 533-537.

103. Radad, K.; Gille, G.; Moldzio, R.; Saito, H.; Ishige, K.; Rausch, W.D. Ginsenosides Rb1 and Rg1 effects on survival and neurite growth of $\mathrm{MPP}^{+}$-affected mesencephalic dopaminergic cells. $J$. Neural. Transm. 2004, 111, 37-45.

104. Wakabayashi, I.; Yasui, K. Wogonin inhibits inducible prostaglandin E2 production in macrophages. Eur. J. Pharmacol. 2000, 406, 477-481.

105. Park, B.K.; Heo, M.Y.; Park, H.; Kim, H.P. Inhibition of TPA-induced cyclooxygenase-2 expression and skin inflammation in mice by wogonin, a plant flavone from Scutellaria radix. Eur. J. Pharmacol. 2001, 425, 153-157.

106. Nakamura, N.; Hayasaka, S.; Zhang, X.Y.; Nagaki, Y.; Matsumoto, M.; Hayasaka, Y.; Terasawa, K. Effects of baicalein, baicalin, and wogonin on interleukin- 6 and interleukin- 8 expression, and nuclear factor-kb binding activities induced by interleukin-1beta in human retinal pigment epithelial cell line. Exp. Eye Res. 2003, 77, 195-202.

107. Suk, K.; Lee, H.; Kang, S.S.; Cho, G.J.; Choi, W.S. Flavonoid baicalein attenuates activationinduced cell death of brain microglia. J. Pharmacol. Exp. Ther. 2003, 305, 638-645.

108. Aschner, M. Astrocytes as mediators of immune and inflammatory responses in the CNS. Neurotoxicology 1998, 19, 269-281.

109. Stollg, G.; Jander, S. The role of microglia and macrophages in the pathophysiology of the CNS. Prog. Neurobiol. 1999, 58, 233-247.

110. Becher, B.; Prat, A.; Antel, J.P. Brain-immune connection: immuno-regulatory properties of CNS-resident cells. Glia 2000, 29, 293-304.

111. Lai, M.Y.; Chen, C.C.; Hou, Y.C.; Hsiu, S.L.; Chao, P.D. Analysis and comparison of baicalin, baicalein and wogonin contents in traditional decoctions and commercial extracts of Scutellariae radix. J. Food Drug Anal. 2001, 9, 145-149. 
112. Hamada, H.; Hiramatsu, M.; Edamatsu, R.; Mori, A. Free radical scavenging action of baicalein. Arch. Biochem. Biophys. 1993, 306, 261-266.

113. Gao, D.; Sakurai, K.; Katoh, M.; Chen, J.; Ogiso, T. Inhibition of microsomal lipid peroxidation by baicalein: a possible formation of an iron-baicalein complex. Biochem. Mol. Biol. Int. 1996, 39, 215-225.

114. Gao, D.; Tawa, R.; Masaki, H.; Okano, Y.; Sakurai, H. Protective effects of baicalein against cell damage by reactive oxygen species. Chem. Pharm. Bull. 1998, 46, 1383-1387.

115. Gao, Z.; Huang, K.; Yang, X.; Xu, H. Free radical scavenging and antioxidant activities of flavonoids extracted from the radix of Scutellaria baicalensis Georgi. Biochim. Biophys. Acta 1999, 1472, 643-650.

116. Gao, Z.; Huang, K.; Xu, H. Protective effects flavonoids in the roots of scutellaria baicalensis georgi against hydrogen peroxide-induced oxidative stress in HS-SY5Y cells. Pharmacol. Res. 2001, 43, 173-178.

117. Shieh, D.E.; Liu, L.T.; Lin, C.C. Antioxidant and free radical scavenging effects of baicalein, baicalin and wogonin. Anticancer Res. 2000, 20, 2861-2865.

118. Kim, Y.O.; Leem, K.; Park, J.; Lee, P.; Ahn, D.K.; Lee, B.C.; Park, H.K.; Suk, K.; Kim, S.Y.; Kim, H. Cytoprotective effect of Scutellaria baicalensis in CA1 hippocampal neurons of rats after global cerebral ischemia. J. Ethnopharmacol. 2001, 77, 183-188.

119. Lee, H.; Kim, Y.O.; Kim, H.; Kim, S.Y.; Noh, H.S.; Kang, S.S.; Cho, G.J.; Choi, W.S.; Suk, K. Flavonoid wogonin from medicinal herb is neuroprotective by inhibiting inflammatory activation of microglia. FASEB J. 2003, 17, 1943-1944.

120. Cho, J.; Lee, H.K. Wogonin inhibits excitotoxic and oxidative neuronal damage in primary cultured rat cortical cells. Eur. J. Pharmacol. 2004, 485, 105-110.

121. Son, D.; Lee, P.; Lee, J.; Kim, H.; Kim, S.Y. Neuroprotective effect of wogonin in hippocampal slice culture exposed to oxygen and glucose deprivation. Eur. J. Pharmacol. 2004, 493, 99-102.

122. Kim, H.; Kim, Y.S.; Kim, S.Y.; Suk, K. The plant flavonoid wogonin suppresses death of activated C6 rat glial cells by inhibiting nitric oxide production. Neurosci. Lett. 2001, 309, $67-71$.

123. Piao, H.Z.; Jin, S.A.; Chun, H.S.; Lee, J.C.; Kim, W.K. Neuroprotective effect of wogonin: potential roles of inflammatory cytokines. Arch. Pharm. Res. 2004, 27, 930-936.

124. O'Neil, L.A.; Kaltschmidt, C. NF-kappa B: a crucial transcription factor for glial and neuronal cell function. Trends Neurosci. 1997, 20, 252-258.

125. Lebeau, A.; Esclaire, F.; Rostène, W.; Pélaprat, D. Baicalein protects cortical neurons from amyloid (25-35) induced toxicity. Neuroreport 2001, 12, 2199-2202.

126. Heo, H.J.; Kim, D.O; Choi, S.J; Shin, D.H.; Lee, C.Y. Potent inhibitory effect of flavonoids in Scutellaria baicalensis on amyloid $\beta$ protein-induced neurotoxicity. J. Agric. Food Chem. 2004, $52,4128-4132$.

127. Zhu, M., Rajamani, S.; Kaylor, J., Han, S., Zhou, F.; Fink, A.L. The flavonoid baicalein inhibits fibrillation of $\alpha$-synuclein and disaggregates existing fibrils. J. Biol. Chem. 2004, 279, 26846-26857.

128. Akao, T.; Kawabata, K.; Yanagisawa, E.; Ishihara, K.; Mizuhara, Y.; Wakui, Y.; Sakashita, Y.; Kobashi, K. Balicalin, the predominant flavone glucuronide of Scutellariae radix, is absorbed 
from the rat gastrointestinal tract as the aglycone and restored to its original form. J. Pharm. Pharmacol. 2000, 52, 1563-1568.

129. Tsai, T.H.; Liu, S.C.; Tsai, P.L.; Ho, L.K.; Shum, A.Y.C.; Chen, C.F. The effects of the cyclosporin A, a P-glycoprotein inhibitor, on the pharmacokinetics of baicalein in the rat: a microdialysis study. Br. J. Pharmacol. 2002, 137, 1314-1320.

130. Zhang, L.; Lin, G.; Chang, Q.; Zuo, Z. Role of intestinal first-pass metabolism of baicalein in its absorption process. Pharm. Res. 2005, 22, 1050-1058.

131. Zhang, L.; Lin, G.; Zuo, Z. Involvement of UDP-glucuronosyltransferases in the extensive liver and intestinal first-pass metabolism of flavonoid baicalein. Pharm. Res. 2007, 24, 81-89.

132. Hanumanthachar, J.; Patil, J.; Milind, P. Potential of phytochemicals in management of cognitive disorders - An update. Phcog. Rev. 2008, 2, 54-60.

133. Kapoor, L.D. CRC Handbook of Ayurvedic Medicinal Plants; CRC Press: Boca Raton, FL; USA, 1990.

134. Singh, R.H.; Narsimhamurthy, K.; Singh, G. Neuronutrient impact of Ayurvedic Rasayana therapy in brain aging. Biogerontology 2008, 9, 369-374.

135. Strimpakos, A.S.; Sharma, R.A. Curcumin: preventive and therapeutic properties in laboratory studies and clinical trials. Antioxid. Redox Signal. 2008, 10, 511-545.

136. Goel, A.; Jhurani, S.; Aggarwal, B.B. Multi-targeted therapy by curcumin: how spicy is it? Mol. Nutr. Food Res. 2008, 52, 1010-1030.

137. Goel, A.; Kunnumakkara, A.B.; Aggarwal, B.B. Curcumin as "Curecumin": from kitchen to clinic. Biochem. Pharmacol. 2008, 75, 787-809.

138. Ganguli, M.; Chandra, V.; Kamboh, M.I.; Johnston, J.M.; Dodge, H.H.; Thelma, B.K.; Juyal, R.C.; Pandav, R.; Belle, S.H.; DeKosky, S.T. Apolipoprotein E polymorphism and Alzheimer disease: the indo-US cross-national dementia study. Arch. Neurol. 2000, 57, 824-830.

139. Lim, G.P.; Chu, T.; Yang, F.; Beech, W.; Frautschy, S.A.; Cole, G.M. The curry spice curcumin reduces oxidative damage and amyloid pathology in an Alzheimer transgenic mouse. J. Neurosci. 2001, 21, 8370-8377.

140. Kim, D.S.; Park, S.Y.; Kim, J.K. Curcuminoids from Curcuma longa L. (Zingiberaceae) that protect PC12 rat pheochromocytoma and normal human umbilical vein endothelial cells from betaA(1-42) insult. Neurosci. Lett. 2001, 303, 57-61.

141. Ono, K.; Hasegawa, K.; Naiki, H.; Yamada, M. Curcumin has potent anti-amyloidogenic effects for Alzheimer's beta-amyloid fibrils in vitro. J. Neurosci. Res. 2004, 75, 742-750.

142. Kim, H.; Park, B.S.; Lee, K.G.; Choi, C.Y.; Jang, S.S.; Kim, Y.H.; Lee, S.E. Effects of naturally occurring compounds on fibril formation and oxidative stress of -amyloid. J. Agric. Food Chem. 2005, 53, 8537-8541.

143. Ringman, J.M.; Frautschy, S.A.; Cole, G.M.; Masterman, D.L.; Cummings, J.L. A potential role of the curry spice in Alzheimer's disease. Curr. Alzheimer Res. 2005, 2, 131-136.

144. Yang, F.; Lim, G.P.; Begum, A.N.; Ubeda, O.J.; Simmons, M.R.; Ambegaokar, S.S.; Chen, P.P.; Kayed, R.; Glabe, C.G.; Frautschy, S.A.; Cole, G.M. Curcumin inhibits formation of amyloid $\beta$ oligomers and fibrils, binds plaques, and reduces amyloid in vivo. J. Biol. Chem. 2005, 280, 5892-5901. 
145. Baum, L.; Ng, A. Curcumin interaction with copper and iron suggests one possible mechanism of action in Alzheimer's disease animal models. J. Alzheimers Dis. 2004, 6, 367-377.

146. Cole, G.M.; Morihara, T.; Lim, G.P.; Yang, F.; Begum, A.; Frautschy, S.A. NSAID and antioxidant prevention of Alzheimer's disease: lessons from in vitro and animal models. Ann. NY Acad. Sci. 2004, 1035, 68-84.

147. Aggarwal, B.B.; Harikumar, K.B. Potential therapeutic effects of curcumin, the anti-inflammatory agent, against neurodegenerative, cardiovascular, pulmonary, metabolic, autoimmune and neoplastic diseases. Int. J. Biochem. Cell Biol. 2008, 41, 40-59.

148. Zhang, L.J.; Wu, C.F.; Meng, X.L.; Yuan, D.; Cai, X.D.; Wang, Q.L. Comparison of inhibitory potency of three different curcuminoid pigments on nitric oxide and tumor necrosis factor production of rat primary microglia induced by lipopolysaccharide. Neurosci. Lett. 2008, 447, $48-53$.

149. Wang, Q.; Sun, A.Y.; Simonyi, A.; Jensen, M.D.; Shelat, P.B.; Rottinghaus, G.E.; MacDonald, R.S.; Miller, D.K.; Lubah, D.E.; Weisman, G.A.; Sun, G.Y. Neuroprotective mechanisms of curcumin against cerebral ischemia-induced neuronal apoptosis and behavioral deficits. $J$. Neurosci. Res. 2005, 82, 138-148.

150. Hansen, J.M. Agriculture in the prehistoric Aegean: data versus speculation. Am. J. Archaeol. 1988, 92, 39-52.

151. Simopoulos, A.P. The Mediterranean diets: what is so special about the diet of Greece? The scientific evidence. J. Nutr. 2001, 131, S3065-S3073.

152. La Vecchia, C.; Bosetti, C. Diet and cancer risk in Mediterranean countries. Hungar. Med. J. 2007, 1, 13-23.

153. Trichopoulou, A.; Lagiou, P.; Kuper, H.; Trichopoulos, D. Cancer and Mediterranean dietary traditions. Cancer Epidemiol. Biomarkers Prev. 2000, 9, 869-873.

154. Visioli, F.; Grande, S.; Bogani, P.; Galli, C. The role of antioxidant in the Mediterranean diets: focus on cancer. Eur. J. Cancer Prev. 2004, 13, 337-343.

155. Johnson, H. Vintage: the Story of Wine; Simon \& Schuster: New York, NY, USA, 1989; pp. 35-46.

156. Phillips, R. A Short History of Wine; HarperCollins: London, UK, 2000; pp. 57-63.

157. Iriti, M.; Faoro, F. Grape phytochemicals: a bouquet of old and new nutraceuticals for human health. Med. Hypotheses 2006, 67, 833-838.

158. Pervaiz, S. Resveratrol: from grapevines to mammalian biology. FASEB J. 2003, 17, 1975-1985.

159. Iriti, M.; Faoro, F. Bioactivity of grape chemicals for human health. Nat. Prod. Commun. 2009, 4, 611-634.

160. Pinder, R.M. Does wine prevent dementia? Int. J. Wine Res. 2009, 1, 41-52.

161. Peters, R.; Peters, J.; Warner, J.; Beckett, N.; Bulpitt, C. Alcohol, dementia and cognitive decline in the elderly: a systematic review. Age Ageing 2008, 37, 505-12.

162. Klatsky, A.L. Moderate drinking reduced risk of heart disease. Alcohol Res. Health 1999, 23, $15-23$.

163. Klatsky, A.L.; Friedman, G.D.; Armstrong, M.A.; Kipp, H. Wine, liquor, beer, and mortality. Am. J. Epidemiol. 2003, 158, 585-595.

164. Charness, M.E. Brain lesions in alcoholics. Alcohol Clin. Exp. Res. 1993, 17, 2-11. 
165. Truelsen, T.; Grønbæk, M.; Schnohr, P.; Boysen, G. Intake of beer, wine and spirits and risk of stroke. The Copenhagen city heart study. Stroke 1998, 29, 2467-2472.

166. Djoussé, L.; Curtis Ellison, R.; Beiser, A.; Scaramucci, A.; D’Agostino, R.B.; Wolf, P.A. Alcohol consumption and risk of ischemic stroke. The Framingham study. Stroke 2002, 33, 907-912.

167. Malarcher, A.M.; Giles, W.H.; Croft, J.B.; Wozniak, M.A.; Wityk, R.J.; Stolley, P.D.; Stern, B.J.; Sloan, M.A.; Sherwin, R.; Price, T.R.; Macko, R.F.; Johnson, C.J.; Earley, C.J.; Buchholz, D.W.; Kittner, S.J. Alcohol intake, type of beverage and risk of cerebral infarction in young women. Stroke 2001, 32, 77-83.

168. Grønbaek, M.; Becker, U.; Johansen, D.; Gottschau, A.; Schnohr, P.; Hein, H.O.; Jensen, G.; Sørensen, T.I.A. Type of alcohol consumed and mortality from all causes, coronary heart disease, and cancer. Ann. Intern. Med. 2000, 133, 411-419.

169. Grønbaek, M. Alcohol/disease risk and beneficial effects. In Encyclopaedia of Human Nutrition; Caballero, B., Ed.; Elsevier: Amsterdam, The Netherland, 2006; pp. 57-62.

170. Conte, A.; Pellegrini, S.; Tagliazucchi, D. Synergistic protection of PC12 cells from $\beta$-amyloid toxicity by reveratrol and catechin. Brain Res. Bull. 2003, 62, 29-38.

171. Ono, K.; Yoshiike, Y.; Takashima, A.; Hasegawa, K.; Naiki, H.; Yamada, M. Potent antiamyloidogenic and fibril-destabilizing effects of polyphenols in vitro: implications for the prevention and therapeutics of Alzheimer's disease. J. Neurochem. 2003, 87, 172-181.

172. Savaskan, E.; Olivieri, G.; Meier, E.; Seifritz, E.; Wirz-Justice, A.; Muller-Spahn, F. Red wine ingredient resveratrol protects from $\beta$-amyloid neurotoxicity. Gerontology 2003, 49, 380-383.

173. Porat, Y.; Abramowitz, A.; Gazit, E. Inhibition of amyloid fibril formation by polyphenols: structural similarity and aromatic interactions as a common inhibition mechanism. Chem. Biol. Drug Des. 2006, 67, 27-37.

174. Rivière, C.; Richard, T.; Vitrac, X.; Mérillon, J.M.; Valls, J.; Monti, J.P. New polyphenols active on -amyloid aggregation. Bioorg. Medic. Chem. Lett. 2008, 18, 828,831.

175. Blanchet, J.; Longpré, F.; Bureau, G.; Morisette, M.; DiPaolo, T.; Bronchti, G.; Martinoli, M.G. Resveratrol, a red wine polyphenol, protects dopaminergic neurons in MPTP-treated mice. Progr. Neuro-Psychopharmacol. Biol. Psych. 2008, 32, 1243-1250.

176. Marambaud, P.; Zhao, H.; Davies, P. Resveratrol promotes clearance of Alzheimer's disease amyloid- $\beta$ peptides. J. Biol. Chem. 2005, 280, 37377-37382.

177. Bastianetto, S.; Zheng, W.H.; Quirion, R. Neuroprotective abilities of resveratrol and other red wine constituents against nitric oxide toxicity in cultured hippocampal neurons. Br. J. Pharmacol. 2000, 131, 711-720.

178. Wang, J.; Ho, L.; Zhao, W.; Seror, I.; Humala, N.; Dickstein, D.L.; Thiyagarajan, M.; Percival, S.S.; Talcott, S.T.; Pasinetti, G.M. Moderate consumption of Cabernet Sauvignon attenuates A neuropathology in a mouse model of Alzheimer's diseases. FASEB J. 2006, 20, 2313-2320.

179. Wang, J.; Ho, L.; Zhao, W.; Ono, K.; Rosensweig, C.; Chen, L.; Humala, N.; Teplow, D.B.; Pasinetti, G.M. Grape-derived polyphenolics prevent A oligomerization and attenuate cognitive deterioration in a mouse model of Alzheimer's disease. J. Neurosci. 2008, 28, 6388-6392.

180. Howitz, K.T.; Bitterman, K.J.; Cohen, H.Y.; Lamming, D.W.; Lavu, S.; Wood, J.G.; Zipkin, R.E.; Chung, P.; Kisielewski, A.; Zhang, L.L.; Scherer, B.; Sinclair, D.A. Small molecule activators of sirtuins extend Saccharomyces cerevisiae lifespan. Nature 2003, 425, 191-196. 
181. Wood, J.G.; Rogina, B.; Lavu, S.; Howitz, K.; Helfand, S.L.; Tartar, M.; Sinclair, D.A. Sirtuin activators mimic caloric restriction and delay ageing in metazoans. Nature 2004, 430, 686-689.

182. Bordone, L.; Guarente, L. Calorie restriction, SIRT1 and metabolism: understanding longevity. Nature Rev. Mol. Cell Biol. 2005, 6, 298-305.

183. Chen, D.; Guarente, L. SIR2: a potential target for calorie restriction mimetics. Trends Mol. Med. 2006, 13, 64-71.

184. Haigis, M.C.; Guarente, L.P. Mammalian sirtuins - emerging roles in physiology, aging and calorie restriction. Genes Develop. 2006, 20, 2913-2921.

185. Outeiro, T.F.; Marques, O.; Kazantsev, A. Therapeutic role of sirtuins in neurodegenerative disease. Biochim. Biophys. Acta 2008, 1782, 363-369.

186. Michan, S.; Sinclair, D. Sirtuins in mammals: insights into their biological function. Biochem. J. 2007, 404, 1-13.

187. Yamamoto, H.; Schoonjans, K.; Auwerx, J. Sirtuin functions in health and disease. Mol. Endocrinol. 2007, 21, 1745-1755.

188. Anekonda, T.S. Resveratrol - a boon for Alzheimer's disease? Brain Res. Rev. 2006, 52, 316-326.

189. Anekonda, T.S.; Reddy, P.H. Neuronal protection by sirtuins in Alzheimer's disease. $J$. Neurochem. 2006, 96, 305-313.

190. Porcu, M.; Chiarugi, A. The emerging therapeutic potential of sirtuin-interacting drugs: from cell death to lifespan extension. Trends Pharmacol. Sci. 2005, 26, 94-103.

191. Lavu, S.; Boss, O.; Elliott, P.J.; Lambert, P.D. Sirtuins - novel therapeutic targets to treat ageassociated diseases. Nature Rev. Drug Discov. 2008, 7, 841-853.

192. Tapsell, L.C.; Hemphill, I.; Cobiac, L.; Patch, C.S.; Sullivan, D.R.; Fenech, M.; Roodenrys, S.; Keogh, J.B.; Clifton, P.M.; Williams, P.G.; Fazio, V.A.; Inge, K.E. Health benefits of herbs and spices: The past, the present, the future. Med. J. Aust. 2006, 185, S4-S24.

193. Ninfali, P.; Mea, G.; Giorgini, S.; Rocchi, M.; Bacchiocca, M. Antioxidant capacity of vegetables, spices, and dressings relevant to nutrition. Brit. J. Nutr. 2005, 93, 257-266.

194. dos Santos-Neto, L.L.; de Vilhena Toledo, M.A.; Medeiros-Souza, P.; de Souza, G.A. The use of herbal medicine in Alzheimer's disease--A systematic review. Evid.-Based Complement. Altern. Med. 2006, 3, 441-445.

195. Bozin, B.; Mika-Dukic, N.; Samojlik, I.; Jovin, E. Antimicrobial and antioxidant properties of rosemary and sage (Rosmarinus officinalis L. and Salvia officinalis L., Lamiaceae) essential oils. J. Agric. Food. Chem. 2007, 55, 7879-7885.

196. Cheung, S.; Tai, J. Anti-proliferative and antioxidant properties of rosemary Rosmarinus officinalis. Oncol. Rep. 2007, 17, 1525-1531.

197. Imanshahidi, M.; Hosseinzadeh, H. The pharmacological effects of Salvia species on the central nervous system. Phytother. Res. 2006, 20, 427-437.

198. Perry, N.S.L.; Houghton, P.J.; Theobald, A.; Jenner, P.; Perry, E.K. In-vitro inhibition of erythrocyte acetylcholinesterase by Salvia lavandulaefolia essential oil and constituent terpenes. J. Pharm. Pharmacol. 2000, 53, 1347-1356. 
199. Tildesley, N.T.J.; Kennedy, D.O.; Perry, E.K.; Ballard, C.G.; Savelev, S.; Wesnes, K.A.; Scholey, A.B. Salvia lavandulaefolia (Spanish Sage) enhances memory in healthy young volunteers. Biochem. Pharmacol. Behav. 2003, 75, 669-674.

200. Savelev, S.U.; Okello, E.; Perry, N.S.L.; Wilkins, R.M.; Perry, E. Synergistic and antagonistic interactions of anticholinesterase terpenoids in Salvia lavandulaefolia essential oil. Biochem. Pharmacol. Behav. 2003, 75, 661-668.

201. Savelev, S.U.; Okello, E.J.; Perry, E.K. Butyryl- and acetyl-cholinesterase inhibitory activities in essential oils of Salvia species and their constituents. Phytother. Res. 2004, 18, 315-324.

202. Tildesley, N.T.J.; Kennedy, D.O.; Perry, E.K.; Ballard, C.G.; Wesnes, K.A.; Scholey, A.B. Positive modulation of mood and cognitive performance following administration of acute doses of Salvia lavandulaefolia essential oil to healthy young volunteers. Physiol. Behav. 2005, 83, 699-709.

203. Moretti, M.D.L.; Peana, A.T.; Satta, M. A study on anti-inflammatory and peripheral analgesic action of Salvia sclarea oil and its main components. J. Essent. Oil Res. 1997, 9, 199-204.

204. Zupkó, I.; Hohmann, J.; Rédei, D.; Falkay, G.; Janicsák, G.; Máthé, I. Antioxidant activity of leaves of Salvia species in enzyme-dependent and enzyme-independent systems of lipid peroxidation and their phenolic constituents. Planta Med. 2001, 67, 366-368.

205. Perry, N.S.L.; Bollen, C.; Perry, E.K.; Ballard, C. Salvia for dementia therapy: review of pharmacological activity and pilot tolerability clinical trial. Pharmacol. Biochem. Behav. 2003, $75,651-659$.

206. Akhondzadeh, S.; Noroozian, M.; Mohammadi, M.; Ohadinia, S.; Jamshidi, A.H.; Khani, M. Salvia officinalis extract in the treatment of patients with mild to moderate Alzheimer's disease: a double blind, randomized and placebo-controlled trial. J. Clin. Pharm. Ther. 2003, 28, 53-59.

207. Lundsberg, L.S. Caffeine consumption. In Caffeine; Spiller, G.A., Ed.; CRC Press: Boca Raton, FL, USA, 1998; pp. 199-224.

208. Cauli, O.; Morelli, M. Caffeine and the dopaminergic system. Behav. Pharmacol. 2005, 16, 63-77.

209. Gu, L.; Gonzalez, F.J.; Kalow, W.; Tang, B.K. Biotransformation of caffeine, paraxanthine, theobromine and theophylline by cDNA-expressed human CYP1A2 and CYP2E1. Pharmacogenet. Genomics 1992, 2, 73-77.

210. Maia, L.; de Mendonca, A. Does caffeine intake protect from Alzheimer's disease? Eur. J. Neurol. 2002, 9, 377-382.

211. Barranco Quintana, J.L.; Allam, M.F.; Serrano Del Castillo, A.R.; Fernandez-Crehuet Navajas, R. Alzheimer's disease and coffee: a quantitative review. Neurol. Res. 2007, 29, 91-95.

212. Ascherio, A.; Weisskopf, M.G.; O'Reilly, E.J. Coffee consumption, gender, and Parkinson's disease mortality in the cancer prevention study II cohort: the modifying effects of estrogen. Am. J. Epidemiol. 2004, 160, 977-984.

213. Ascherio, A.; Zhang, S.M.; Hernan, M.A. Prospective study of caffeine consumption and risk of Parkinson's disease in men and women. Ann. Neurol. 2001, 50, 56-63.

214. Ascherio, A.; Chen, H. Caffeinated clues from epidemiology of Parkinson's disease. Neurology 2003, 61, S51-S54. 
215. al'Absi, M.; Lovallo, W.R. Caffeine effects on the human stress axis. In Coffee, tea, chocolate and the brain; Nehlig, A., Ed.; CRC Press: Boca Raton, FL, USA, 2004; pp. 113-131.

216. Khokhar, S.; Magnusdottir, S.G. Total phenol, catechin, and caffeine contents of teas commonly consumed in the United kingdom. J. Agric. Food Chem. 2002, 50, 565-570.

217. Perva-Uzunalic, A.; Skerget, M.; Knez, Z.; Weinreich, B.; Otto, F.; Grüner, S. Extraction of acive ingredients from green tea (Camelia sinensis): Extraction efficiency of major catechins and caffeine. Food Chem. 2006, 96, 597-605.

218. Kuriyama, S.; Hozawa; A.; Ohmori, K.; Shimazu, T.; Matsui, T.; Ebihara, S.; Awata, S.; Nagatomi R.; Arai, H.; Tsuji, I. Green tea consumption and cognitive function: a cross-sectional study from the Tsurugaya Project 1. Am. J. Clin. Nutr. 2006, 83, 355-361.

219. Nagao, T.; Komine, Y.; Soga, S.; Meguro, S.; Hase, T.; Tanaka, Y.; Tokimitsu, I. Ingestion of a tea rich in catechins leads to a reduction in body fat and malondialdehyde-modified LDL in men. Am. J. Clin. Nutr. 2005, 81, 122-129.

220. Sasazuki, S.; Kodama, H. Relation between green tea consumption and the severity of coronary atherosclerosis among Japanese men and women. Ann. Epidemiol. 2000, 10, 401-408.

221. Chen, D.; Daniel, K.G.; Kuhn, D.J.; Kazi, A.; Bhuiyan, M.; Li, L.; Wang, Z.; Wan, S.B.; Lam, W.H.; Chan, T.H.; Dou, Q.P. Green tea and tea polyphenols in cancer prevention. Front Biosci. 2004, 9, 2618-2631.

222. Coimbra, S.; Castro, E.; Rocha-Pereira, P.; Rebelo, I.; Rocha, S.; Santos-Silva, A. The effect of green tea in oxidative stress. Clin. Nutr. 2006, 25,790-796.

223. Huh, S.W.; Bae, S.M.; Kim, Y.W.; Lee, J.M.; Namkoong, S.E.; Lee, I.P.; Kim, S.H.; Kim, C.K.; Ahn, W.S. Anticancer effects of (-)-epigallocatechin-3-gallate on ovarian carcinoma cell lines. Gynecol Oncol. 2004, 94, 760-768.

224. Hussain. T.; Gupta, S.; Adhami, V.M.; Mukhtar, H. Green tea constituent epigallocatechin-3gallate selectively inhibits COX-2 without affecting COX-1 expression in human prostate carcinoma cells. Int. J. Cancer. 2005, 113, 660-669 .

225. Larsson, S.C.; Wolk, A. Tea consumption and ovarian cancer risk in a population-based cohort. Arch. Intern. Med. 2005, 165, 2683-2686.

226. Muraki, S.; Yamamoto, S.; Oka, H.; Yoshimura, N.; Kawaguchi, H.; Orimo, H.; Nakamura, K. Green tea drinking is associated with increased bone mineral density in elderly women. In Study P187SA, Proceedings of the International Osteoporosis Foundation World Congress on Osteoporosis, Toronto, Canada, June 5, 2006.

227. Sakanaka, S.; Okada, Y. Inhibitory effects of green tea polyphenols on the production of a virulence factor of the periodontal-disease-causing anaerobic bacterium Porphyromonas gingivalis. J. Agric. Food Chem. 2004, 52, 1688-1692.

228. Sano, J.; Inami, S.; Seimiya, K.; Ohba, T.; Sakai, S.; Takano, T.; Mizuno K. Effects of green tea intake on the development of coronary artery disease. Circ. J. 2004, 8, 665-670.

229. Siddiqui, I.A.; Afaq, F.; Adhami, V.M.; Ahmad, N.; Mukhtar, H. Antioxidants of the beverage tea in promotion of human health. Antioxid. Redox Signal. 2004, 6, 571-582.

230. Song, J.M.; Lee, K.H.; Seong, B.L. Antiviral effect of catechins in green tea on influenza virus. Antiviral Res. 2005, 68, 66-74. 
231. Mandel, S.; Youdim, M.B. Catechin polyphenols: neurodegeneration and neuroprotection in neurodegenerative diseases. Free Radic. Biol. Med. 2004, 37, 304-317.

232. Reznichenko, L., Amit, T., Zheng, H.; Avramovich-Tirosh, Y.; Youdim, M.B., Weinreb, O.; Mandel, S. Reduction of iron-regulated amyloid precursor protein and beta-amyloid peptide by ()-epigallocatechin-3-gallate in cell cultures: implications for iron chelation in Alzheimer's disease. J. Neurochem. 2006, 97, 527-536.

233. Weinreb, O.; Mandel, S.; Amit, T.; Youdim, M.B. Neurological mechanisms of green tea polyphenols in Alzheimer's and Parkinson's diseases. J. Nutr. Biochem. 2004, 15, 506-516.

234. Haque, A.M.; Hashimoto, M.; Katakura, M.; Tanabe, Y.; Hara, Y.; Shido, O. Long-term administration of green tea catechins improves spatial cognition learning ability in rats. J. Nutr. 2006, 136, 1043-1047.

235. Gray, J. Caffeine, coffee and health. Nutr. Food Sci. 1998, 6, 314-319.

236. Iriti, M.; Faoro, F. Chemical diversity and defence metabolism: how plants cope with pathogens and ozone pollution. Int. J. Mol. Sci. 2009, 10, 3371-3399.

237. Schmitt-Schillig, S.; Schaffer, S.; Weber, C.C.; Eckert, G.P.; Müller, W.E. Flavonoids and the aging brain. J. Physiol. Pharmacol. 2005, 56, 23-36.

238. Peng, H.W.; Cheng, F.C.; Huang, Y.T.; Chen, C.F.; Tsai, T.H. Determination of naringinin and its glucoronide conjugate in rat plasma and brain tissue by high-performance liquid chromatography. J. Chromat. 1998, 714, 369-374.

239. Tsai, T.H.; Chen, Y.F. Determination of unbound hesperetin in rat blood and brain by microdialysis coupled to microbore liquid chromatography. J. Food Drug Anal. 2000, 8, 331-336.

240. Abd El Mohsen, M.M.; Kuhnle, G.; Rechner, A.R. Uptake and metabolism of epicatechin and its access to the brain after oral ingestion. Free Rad. Biol. Med. 2002, 33, 1693-1702.

241. Youdim, K.A.; Dobbie, M.S.; Kuhnle, G. Interaction between flavonoids and the blood-brain barrier: in vitro studies. J. Neurochem. 2003, 85, 180-192.

242. Youdim, K.A.; Shukitt-Hale, B.; Joseph, J.A. Flavonoids and the brain: interactions at the bloodbrain barrier and their physiological effects on the central nervous systems. Free Rad. Biol. Med. 2004, 37, 1683-1693.

243. Tamatani, M.; Che, Y.H.; Matsuzaki, H.; Ogawa, S.; Okado, H.; Miyake, S.; Mizuno, T.; Tohyama, M. Tumor necrosis factor induces Bcl-2 and Bcl-x expression through NFkB activation in primary hippocampal neurons. J. Biol. Chem. 1999, 274, 8531-8538.

244. Manach, C.; Scalbert, A.; Morand, C.; Rémésy, C.; Jimenez, L. Polyphenols - food sources and bioavailability. Am. J. Clin. Nutr. 2004, 79, 727-747.

245. Manach, C.; Williamson, G.; Morand, C.; Scalbert, A.; Remesy, C. Bioavailability and bioefficacy of polyphenols in humans. I. Review of 97 bioavailability studies Am. J. Clin. Nutr. 2005, 81, 230S-242S.

246. Williamson, G.; Manach, C. Bioavailability and bioefficacy of polyphenols in humans. II. Review of 93 intervention studies. Am. J. Clin. Nutr. 2005, 81, 243S-255S.

247. Gilgun-Sherki, Y.; Melamed, E.; Offen, D. Oxidative stress induced-neurodegenerative disease: the need for antioxidants that penetrate the blood brain barrier. Neuropharmacology 2001, 40, 959-975. 
248. Dajas, F.; Rivera-Megret, F.; Blasina, F.; Arredondo, F.; Abin-Carriquiry, J.A.; Costa, G.; Echeverry, C.; Lafon, L.; Heizen, H.; Ferreira, M.; Morquio, A. Neuroprotection by flavonoids. Braz. J. Med. Biol. Res. 2003, 36, 1613-1620.

249. Ramassamy, C. Emerging role of polyphenolic compounds in the treatment of neurodegenerative diseases: a review of their intracellular targets. Eur. J. Pharmacol. 2006, 545, 51-64.

(C) 2010 by the authors; licensee MDPI, Basel, Switzerland. This article is an open-access article distributed under the terms and conditions of the Creative Commons Attribution license (http://creativecommons.org/licenses/by/3.0/). 